\title{
ВЛИЯНИЕ СТРОЕНИЯ ПЕКТИНОВЫХ ВЕЩЕСТВ ЛЬНЯНЫХ КОРМОВЫХ ДОБАВОК НА АБСОРБЦИОННОЕ СВЯЗЫВАНИЕ АЗАГЕТЕРОЦИКЛИЧЕСКИХ МИКОТОКСИНОВ
}

\author{
С.А. Кокшаров, С. В. Алеева, О. В. Лепилова \\ СЕРГЕЙ АЛЕКСАНДРОВИЧ КОКШАРОВ - доктор технических наук, профессор, Институт химии \\ растворов им. Г.А. Крестова РАН, лаборатория «Химия и технология модифицированных волокнистых \\ материалов», главный научный сотрудник. Область научных интересов: физико-химические основы \\ структурного модифицирования биополимерных, волокнистых и композиционных материалов. \\ E-mail: ksa@isc-ras.ru.
}

СВЕТЛАНА ВЛАДИМИРОВНА АЛЕЕВА - доктор технических наук, Институт химии растворов им. Г.А. Крестова РАН, лаборатория «Химия и технология модифицированных волокнистьх материалов», ведущий научный сотрудник. Область научных интересов: физико-химические основы биохимического модифицирования растительного сырья и волокнистых материалов. E-mail: sva@isc-ras.ru.

ОЛЬГА ВЛАДИМИРОВНА ЛЕПИЛОВА - кандидат технических наук, Институт химии растворов им. Г.А. Крестова РАН, лаборатория «Химия и технология модифицированных волокнистых материалов», старший научный сотрудник. Область научных интересов: кинетика и термодинамика адсорбционных процессов с участием биополимерных и волокнистыхматериалов. E-mail: lov@isc-ras.ru.

153045, г. Иваново ул. Академическая, д. 1, Институт химии растворов им. Г.А. Крестова РАН, лаборатория «Химия и технология модифицированных волокнистых материалов».

В статье представлен комплексный подход к исследованию особенностей химического и надмолекулярного строения пектиновых вещуеств из растительных тканей льняного стебля во взаимосвязи с закономерностями проявления сорбционных свойств полиуронидов в отношении теофиллина, выбранного в качестве модели азагетероциклических микотоксинов. Сохранность структуры выделяемых пектиновых вещеетв обеспечивали благодаря использованию методов ферментативной деструкции нейтральных полисахаридов льна и ультразвуковой активации экстракционных процессов. В экспериментальных исследованиях использовань методы Фурье-ИК-спектроскопии, вискозиметрии, ИК-спектрометрии пленок пектина, стациионарной сорбции из ограниченного объема, электронной спектроскопии растворов. Анализ результатов сорбционных исследований проведен с использованием диффузионных моделей Бойда, Морриса-Вебера и гелевой диффузии, кинетических моделей Лагергрена, Хо и Маккея. На основании данных о химическом состоянии полиуронидов предложены модели молекулярного строения полимерной цеепи и пространственного взаимодействия между макромолекулами в структуре сорбирующего зерна. Прослежено влияние структурной организации полиуронидов на уровень равновесной сорбции в интервале рН 2-6,5, на характеристики внешне- и внутридиффузионного лимитирования массопереноса, а также на константу скорости сорбции и уровень предельной сорбции биополимера. Результать исследований позволяют прогнозировать сорбционное связывание алкалоидов пектиновыми субстратами на основании данных о соотношении форм галактуронатных звеньев и обеспечить комплексное решение актуальных задач оптимизации кормления жвачных животных, включая предупреждение микотоксикоза многочисленными видами азагетероциклических микотоксинов.

Ключевые слова: пектины растительных тканей льна, химическое состояние галактуронатных звеньев, надмолекулярная структура пектина, абсорбция теофиллина, моделирование диффузионных и кинетических параметров сорбции. 


\title{
INFLUENCE OF PECTIN STRUCTURE IN THE FLAX FEED ADDITIVES ON THE ABSORPTION BINDING WITH AZAHETEROCYCLIC MYCOTOXINS
}

\author{
S.A. Koksharov, S. V. Aleeva, O. V. Lepilova \\ 153045, Ivanovo, Russia Akademicheskaya str., 1, G.A. Krestov Institute of Solution Chemistry of the Russian \\ Academy of Sciences.
}

The integrated approach to the study of the peculiarities of the chemical and supramolecular structure of pectins from plant tissues flax stem and to their influence on the regularities of the sorption properties polyuronides to, theophylline which was chosen as a model of azaheterocyclic micotoxins was presented in the article. The structure of the extracted pectins was preserved thanks to the use of enzymatic destruction neutral flax polysaccharides and ultrasonic activation of extraction processes. In experimental studies FT-IR spectroscopy, viscometry, IR spectroscopy of pectin films, stationary sorption from a limited volume and electron spectroscopy of solutions were used. The results from sorption studies were analyzed using Boyd, Morris-Weber and gel diffusion models and also Lagergren, Ho and McKay kinetic models. Models of the molecular structure of the polymer chain and the spatial interaction between macromolecules in the structure of the sorbing particles are proposed using as a base the data described the chemical state of polyuronides. The effect of the structural organization polyuronides on the level of equilibrium sorption at the $\mathrm{pH}$ 2-6.5, on the characteristics of external and internal diffusion limiting of mass transfer and also on the absorption rate constant and the level of maximum biopolymer sorption was fixed. The results of the study allow to prognosis the sorption binding of alkaloids by pectin substrates based on data describing the ratio forms of galacturonate units and provide a complex decision of actual problems for optimization of ruminant feeding including the prevention of mycotoxicosis by numerous types of azageterocyclic mycotoxins.

Keywords: pectins from plant tissues flax, chemical state of galacturonate units, supramolecular structure of pectin, theophylline absorption, modeling of diffusion and kinetic sorption parameters.

\section{Введение}

Химия и технология пектина претерпевают новый виток бурного развития. Наряду с традиционными сферами применения биополимера в пищевой и фармацевтической промышленности растет интерес к использованию его способности к различным видам взаимодействий для получения новых функционализированных материалов. В частности, разработка специальных методов модификации обеспечивает получение самосшитых гидрогелей пектина с фиброином шелка, обладающих высокой механической прочностью и переменными свойствами, которые представляют интерес в инженерии костной ткани [1]. Управление структурной организацией гидрогелей пектина с хитозаном и нанокристаллической целлюлозой позволяет получать биофункциональные инъекционные материалы для тканевой инженерии [2]. Пектин используется в качестве структурирующей добавки в составе полиэфиримидных ультрафильтрационных мембран [3].
Повышенное внимание уделяется вопросам управления свойствами пектиновых веществ непосредственно в структуре материалов растительной природы. С учетом расширения сфер практического применения композитных материалов армированных льняными волокнами большое значение имеют исследования кооперативного действия пектиновой матрицы в структуре волокон и полимерного связующего в межволоконных пространствах [4], а также влияния условий микробиологической обработки льняных стеблей на свойства выделяемых технических волокон и свойства формируемых композитов [5].

Пектиновые вещества являются важным многофункциональным компонентом в составе кормовых фитодобавок. Разработка физико-химических подходов к решению актуальных задач в развитии кормовой базы для высокопродуктивного сельскохозяйственного животноводства в значительной степени связана с обоснованием методов управления совокупностью адсорбционных взаимодействий, протекающих с участием полиуронидов 
в специфических условиях многостадийных пищеварительных процессов.

В частности, организация рационального питания жвачных животных базируется на том, что биохимические превращения кормовой массы начинаются уже на первой стадии ее пребывания в преджелудке (rumen - рубец), и эти процессы вносят преимущественный вклад в обеспечение углеводными компонентами $[6,7]$. При этом аминокислотная потребность удовлетворяется за счет более позднего расщепления кормового белка при прохождении кишечника $[8,9]$. В исследовании этих процессов появляется много новых интересных сообщений.

Проблема защиты белка от преждевременного расщепления решается разными способами, в том числе за счет поиска и введения в рацион растительных добавок с протеинами, устойчивыми к ферментативному воздействию микроорганизмов, развивающихся в рубце [10-13]. Применяются методы термической денатурации протеина или химической модификации, например, формальдегидом [14-16]. Имеются рекомендации по применению аминокислот в химически связанной форме $[17,18]$. Вместе с тем специалисты отмечают, что повышенная степень защиты белка может привести к снижению продуктивности крупного рогатого скота в связи с недостаточностью азотного питания для развития микрофлоры рубца, а также с низким усвоением трансформированных протеинов в отделах кислотного пищеварения [19].

Компромиссный вариант могут обеспечить сорбционные методы обратимого связывания белковых веществ соединениями поликатионной и полианионой природы [20], в том числе с применением пектинсодержащего растительного сырья [2123]. С учетом меняющейся степени кислотности в разных органах пищеварительного тракта жвачных животных большое значение имеет влияние показателя $\mathrm{pH}$ среды на прочность взаимодействия протеинов с пектиновыми веществами [24]. Нами показано, что для повышения адсорбционной способности фитодобавок важно обеспечить высвобождение пектинов из сетчатых структур связующего вещества в межклетниках и срединных пластинках растительных объектов [25-28]. Выявленные закономерности получили воплощение в специализированных методах ферментативного модифицирования льняных материалов, используемых в композиции с высокопротеиновыми концентратами для обеспечения $85 \%$-ной устойчивости белковых веществ к расщеплению микрофлорой рубца [29]. Результаты согласуются с недавно опубликованными данными оценки эффективности ис- пользования льно-протеиновых кормовых добавок in vivo [30].

Для повышения полноты использования питательных веществ грубых кормов применяются методы силосования под действием спонтанной микрофлоры, либо биомодифицирования с применением подобранных микробных композиций [31, 32]. В ходе этих процессов, а также при нарушении условий хранения кормов повышается риск поражения биомассы микотоксинами - вторичными метаболитами ряда микроскопических грибов, представляющими серьезную угрозу, как для домашнего скота, так и для здоровья людей. Известно более 300 разновидностей токсичных соединений микробного происхождения, подразделяемых с учетом особенностей их молекулярного строения. Характеристика наиболее распространенных и опасных веществ представлена в обзорах [33-35].

Наряду с использованием специальных физических и химических методов подготовки кормов для предупреждения микотоксикозов наиболее распространенной профилактической мерой является применение адсорбентов. Выбор сорбента осуществляется с учетом полярности нейтрализуемых соединений $[36,37]$. В частности, эффективность применения алюмосиликатов подтверждена в отношении полярных веществ, например, афлотоксинов. Активированный уголь лучше связывает гидрофобные микотоксины, не содержащие полярных групп, в частности, полициклические ароматические соединения трихоценового типа. Сферу использования растительных сорбентов связывают с активностью бета-глюканов в отношении соединений, содержащих алифатические или ароматические гидроксилы, таких как, зераленон, фумонизины, ахротоксины [38, 39]. Детоксикация животных с помощью пектинсодержащего цитрусового сырья продемонстрирована в тестах in vivo [40].

На территории РФ оценка качества сельскохозяйственных кормов проводится с учетом максимально допустимого уровня (МДУ) микотоксинов, параметры которого регламентированы для ограниченного круга наиболее распространенных и опасных соединений [41]. Например, величина МДУ для содержания афлотоксина в растительных кормах составляет 0,05 мг/кг. Практически регистрируемое содержание отдельных соединений этой группы, как правило, на 1-2 десятичных прядка ниже МДУ. Вместе с тем известно, что применяемых мер защиты от мажорных токсинов может быть недостаточно, поскольку их действие суммируется с влиянием других одновременно присутствующих опасных веществ с возможным проявлением синергизма [42]. В связи с этим повышает- 
ся актуальность комплексного использования сорбентов разной природы для обеспечения взаимодополняющих эффектов профилактики микотоксикозов.

Функцию дополнительного средства детоксикации организма животных могут выполнять пектиновые вещества, проявляя активность в кислых отделах пищеварительного тракта по отношению к широкой группе азагетероциклических соединений. Химическое строение нескольких представителей группы алкалоидов показано на рис. 1. В число мажорных микотоксинов включены эрготамин (I), циклопиазоновая кислота (II) и рокефортин (III), вырабатываемые широко распространенными универсальными сапрофитами родов Penicillium и Aspergillus. Растительные корма и силос часто бывают поражены метаболитами грибов рода Alternaria, в их числе тенуазоновая кислота (IV) и макузолин (V) [43]. Серьезную опасность представляют, рассмотренные в обзоре [44] треморгенные и нейротоксичные индол-терпены производные паспалина (VI).

Сходство представленных на схеме соединений состоит в том, что они плохо растворяются в воде и нейтральных водных системах, но в кислой среде обретают растворимость и диффузионную подвижность за счет протонирования атомов азота с неподеленной электронной парой. Правомерно ожидать, что молекулы протонированных алкалоидов способны к эффективному взаимодействию с пектиновыми веществами в составе стаби- лизирующей кормовой фитодобавки по методу [29]. Для этого имеются объективные предпосылки, поскольку пектины, выполнив свои функции защиты белка в рубце и попадая в основной отдел желудка (сычуг) с сильнокислой средой ( $\mathrm{pH} 1,5-2,5)$, освобождаются от протеинов в результате подавления диссоциации карбоксильных групп. Возобновление активности пектинов происходит при попадании в двенадцатиперстную кишку, на входе в которую уровень рН составляет 4,5 ед., на выходе 6,8 ед. Очевидно эти параметры определяют практикуемые условия проведения испытаний связывающей способности энтеросорбентов в тестах in vitro [45].

Длина двенадцатиперстной кишки у жвачных животных значительно больше, по сравнению с человеческим органом (50 см у коз и овец, 120 см у коров и до 200 см у быков, буйволов). Длительность пребывания перевариваемого корма в этом участке кишечника коровы не превышает 30 мин. Оценка кинетических характеристик сорбционного процесса позволит обосновать нормы введения пектинсодержащей фитодобавки для предупреждения всасывания микотоксинов в последующих участках кишечника и для уменьшения нагрузки на физиологическую систему детоксикации животных.

Пектиновые вещества из различных растительных источников имеют существенные отличия в долевом соотношении галактуронатных звеньев с незамещенной карбоксильной группой, а также в метоксилированной и кальций-пектатной<smiles>O=C(NC1OC2(O)C3CCCN3C(=O)C(Cc3ccccc3)N2C1=O)C1C=C2c3cccc4[nH]cc(c34)CC2NC1</smiles>

I<smiles>CC(=O)C1=C(O)C2C3c4c[nH]c5cccc(c45)CC3C(C)(C)N2C1=O</smiles>

II<smiles>C=CC(C)(C)C12CC3C(=O)N/C(=C\c4cnc[nH]4)C(=O)N3C1Nc1ccccc12</smiles>

III<smiles>CCC(C)C1NC(=O)C(C(C)=O)C1=O</smiles>

IV<smiles>O=C1NC(Cc2ccccc2)C(=O)C2CC(O)CC12</smiles>

V<smiles>CCOCC1OC2CCC3C4CCC(CO)OC4CCC3C2c2[nH]c3ccccc3c21</smiles>

VI

Рис. 1. Схемы строения микотоксинов из группы гетероциклических алкалоидов 
формах. Строение пектинов в льняных материалах также значимо варьирует в зависимости от генотипа (селекционного сорта) льна-долгунца, условий онтогенеза и переработки растительного сырья [46-49]. Необходимость анализа специфического проявления сорбционной активности пектиновых веществ в отношении азотсодержащих микотоксинов подтверждают ранее выявленные закономерности влияния химического строения гомогалактуронанов на сорбционное связыванием ионов металлов и полярных органических соединений с дифференциацией вклада различных механизмов протекания адсорбционных взаимодействий $[50,51]$. Принимая во внимание широкое использование алюмосиликатных сорбентов для профилактики микотоксикозов, большое научно-практическое значение имеет моделирование сорбции алкалоидов бинарными полимер-неорганическими системами с учетом ранее выявленного усиления взаимного действия компонентов пектин-монтмориллонитных комплексов в отношении неорганических и органических поллютантов $[52,53]$.

Цель проведенных исследований состояла в выявлении закономерностей «состав - свойство» при описании кинетики сорбции гетероциклических соединений производных имидазола и пиразола пектиновыми сорбентами с учетом данных об особенностях строения полиуронидов в различных растительных тканях льняного стебля, отделяемых с разными видами вторичных продуктов льноперерабатывающего производства, для моделирования эффективности связывания микотоксинов льносодержащими кормовыми добавками для жвачных животных.

\section{Экспериментальная часть}

\section{Материаль}

В качестве модели азагетероциклических микотоксинов применяли соединение, представляющее собой систему из пиримидинового и имидазольного циклов с двумя общими углеродными атомами и относящееся к группе пуриновых оснований, а именно 1,3-диметил-7Н-пурин-2,6-дион:<smiles>Cn1c(=O)c2[nH]cnc2n(C)c1=O</smiles>

Тривиальное название - теофиллин. Препарат применяется в качестве пестицида и медицинского средства. По величине показателя ЛД 50 (225 мг/кг) вещество относится к 3-му классу опасности (умеренно опасные вещества), что позволяет использовать его при проведении экспериментальных химических исследований. В работе применяли фармацевтическую форму препарата (производитель АО Валента Фарм, Россия).

Исследуемые пектиновые вещества выделяли из трех разновидностей побочной продукции (by-products) промышленной переработки льнадолгунца Linum usitatissimum L.: костра (flax shive), пакля (tow) и вытряска (flocks). Производители: ООО «Корона» (г. Иваново), ООО «Льняная мануфактура Кузьмина» (Новосибирская обл.).

При выделении пектиновых веществ моделировали процесс биорасщепления углеводных компонентов растительного корма в рубце жвачных животных с применением ферментов, катализирующих гидролиз целлюлозы, ксиланов и глюканов без повреждения полиуронидов [54]. Биообработку льноматериалов препаратом ЦеллоЛюкс-F (производитель ООО «Сиббиофарм», г. Новосибирск) осуществляли при температуре раствора $40{ }^{\circ} \mathrm{C}$ и рН 7 в течение 6 часов.

Пектин экстрагировали горячей $\left(92{ }^{\circ} \mathrm{C}\right)$ водой при воздействии ультразвука в соответствии с рекомендациями [55]. Обработку осуществляли в дезинтеграторе УЗДН-2Т при частоте 22 Гц. Осаждение пектина проводили путем введения в экстракт $96 \%$-ного этанола в соотношении 1:3, отделяемый пектиновый коагулят промывали 70 и 96 \%-ным этиловым спиртом и сушили при $60{ }^{\circ} \mathrm{C}$.

Специфика препарирования пектинов льняной костры предусматривала первоначальную экстракцию водорастворимых фракций теплой $\left(40^{\circ} \mathrm{C}\right)$ водой при перемешивании в течение 8 ч.

В качестве образца сравнения эффективно действующего сорбента использовали препарат алюмосиликатной природы - Na-монтмориллонит марки (Мт) Cloisite ${ }^{\circledR} \mathrm{Na}$ фирмы «Southern Clay Products, Inc.» (США) квалификации «х.ч.» с катион-обменной емкостью 92,6 мг-экв/100 г.

Для получения бикомпонентных систем пектин-монтмориллонит адаптировали метод получения монтмориллонит-крахмальных композитов [56]. Предварительно готовили кашицу монтмориллонита в дистиллированной воде для его набухания (соотношение Мт : вода составляет 70 : 30). Далее навеску порошковой формы полиуронида смешивали с частицами набухшего глинистого минерала в процентном соотношении 80:20 с обработкой на вибрационной мельнице (режимные параметры установки: частота вибраций активатора - 50 Гц, амплитуда колебаний - 180 мкм, виброскорость - 158 мм/с, ви- 
броускорение - 140 м/с² , длительность воздействия - 30 мин). Полученный композит высушивали при температуре $40{ }^{\circ} \mathrm{C}$ в течение 1 ч (вакуумная сушка 66,5 кПа) с дальнейшей выдержкой в эксикаторе с хлористым кальцием.

\section{Приборы и методы анализа}

Идентификацию пектинов осуществляли методом ИК-Фурье-спектроскопии. ИК-спектры записаны на инфракрасном Фурье-спектрометре Vertex 80v фирмы Bruker в диапазоне частот $400 \ldots 4000 \mathrm{~cm}^{-1}$ с разрешением $2 \mathrm{~cm}^{-1}$. Образцы подготовлены в виде спрессованных таблеток из смеси пектина и порошка $\mathrm{KBr}$ в соотношении $1: 150$.

Анализ соотношения галактуронатных звеньев пектина в незамещенной, метоксилированной и кальций-пектатной формах проводили с применением метода ИК-спектрометрии пленок пектиновых веществ, который основан на измерении интенсивности изолированной полосы валентных колебаний связи $v_{\text {as }}(\mathrm{C}-\mathrm{OMe}) 1615 \mathrm{~cm}^{-1}$, характеризующей поглощение пектинатов с одно- и двухвалентными ионами металлов [57]. Эксперимент предусматривает проведение цикла операций для получения модифицированных препаратов посредством последовательного химического превращения мономеров свободной галактуроновой кислоты и метоксилированных звеньев в форму пектата кальция [50]. Спектры снимали на спектрофотометре AVATAR-360 в режиме на пропускание в области частот 500-4000 $\mathrm{cm}^{-1}$.

Для определения степени полимеризации тканевых пектинов препараты предварительно подвергали декальцинированию $0,1 \mathrm{~N}$ раствором $\mathrm{NaOH}$ в течение 1 ч при комнатной температуре. По данным кинематической вязкости ( $)$ 0,1-1 \%-ных гидрогелей пектина, измеряемой с помощью капиллярного вискозиметра Оствальда, из зависимостей $\eta_{y \delta} / c=f(c)$ и $\ln \left(\left(\eta / \eta_{0}\right) / c\right)=f(c)$ графически определяли характеристическую вязкость $[\eta]$.

По уравнению Марка-Куна-Хаувинка рассчитали молекулярную массу $\left(M_{r}\right)$ :

$$
[\eta]=\mathrm{K} \cdot M_{r}^{a},
$$

где К и $a$ - коэффициенты, характеризующие взаимодействие полимера с растворителем и форму макромолекулы, $\mathrm{K}=1,1 \cdot 10^{-5} ; a=1,22$.

Степень полимеризации вычисляли по формуле:

$$
C \Pi=M_{r} / \mathrm{M}_{\Gamma К}
$$

где $\mathrm{M}_{г К}=194$ г/моль - молярная масса галактуроновой кислоты.
Анализ сорбции теофиллина осуществлен в статических условиях из ограниченного объема при температуре $40{ }^{\circ} \mathrm{C}$ и варьируемых значениях pH 2,0-6,5, создаваемых фосфатными буферными растворами. Для получения кинетических кривых сорбции в серию мерных колб помещали 5 мл 0,5 \% раствора пектина и 20 мл теофиллина для обеспечения начальной концентрации сорбата $\left(\mathrm{C}_{0}\right) 2 \mathrm{MM} /$ л в суммарном объеме раствора. Количество образцов в серии обеспечивает последовательное проведение анализа через определенные промежутки времени $(t)$ в течение 120 мин. Для анализа реакционную смесь испытуемого образца центрифугировали 10 мин при 2000 об/мин для отделения сорбента и определения текущей концентрации теофиллина в супернатанте $\left(\mathrm{C}_{\tau}\right)$ методом электронной спектроскопии по его поглощению при 270 нм на UV/VIS спектрофотометре Unico 2800. Количество теофиллина в сорбенте в момент времени $t$ $\left(q_{t}\right.$, ммоль/г) рассчитывали по уравнению:

$$
q_{t}=\left(C_{0}-C_{\tau}\right) \mathrm{V} / m \mathrm{M}_{\mathrm{T}},
$$

где $\mathrm{M}_{\mathrm{T}}=184$ г/моль - молярная масса теофиллина; $m$ - масса навески сорбента, г.

Для анализа кинетических закономерностей сорбции использованы диффузионные модели Бойда [58], Морриса-Вебера [59] и гелевой диффузии [60], а также кинетические модели псевдо-первого порядка Лагергрена и псевдо-второго порядка Хо и Маккея [61-63].

\section{Результаты и обсуждение}

\section{Характеристика исследуемых льняных субстратов и полиуронидных препаратов}

Используемые в работе льноматериалы являются побочными продуктами на последовательных стадиях механической обработки сырья для выделения льняного волокна. В рамках выполняемого исследования важное отличие объектов состоит в том, что в каждом из них преимущественно содержатся пектины из разных растительных тканей льняного стебля.

При обработке льняной тресты на мяльной машине (breaking machine) происходит дробление внутренней, древесной части стебля. В отделяемых частицах льняной костры (shive) основным пектинсодержащим компонентом являются проводящие ткани - ксилема (xylem). В процессе трепания (scutching) волокнистые пучки отделяют от периферийного слоя стебля, чему способствует микробиологическая деструкция его компонентов в процессе лугового расстила или, как принято 
называть, росяной мочки (dew retting) льняного сырья. Побочным продуктом трепания является пакля (tow), которая содержит спутанные непрядомые волокнистые комплексы с остатками плохо расщепленных клеток паренхимы (parenchyma), окружавшей лубяные пучки. Вытряска (flocks) это отходы обработки на чесальной и трясильной машинах (hackling machin \& tow shaker). Преимущественно этот материал содержит пуховую фракцию коротких волокон льна с пектинами в клеточной стенке волокон и срединных пластинках лубяных пучков (bast bundles).

Таким образом, сравниваемые препараты выделенных полиуронидных субстратов нами классифицированы и обозначены как пектин луба $\left(\mathrm{P}_{\mathrm{BAST}}\right)$, пектин паренхимы $\left(\mathrm{P}_{\mathrm{PAR}}\right)$ и пектин ксилемы $\left(\mathrm{P}_{\mathrm{XYL}}\right)$. Для обобщения этой группы образцов будем использовать наименование тканевые пектины. Вместе с тем в процессе препарирования льняной костры выявлено присутствие в субстрате водорастворимых полиуронидов, которые не могут быть компонентом клеточных стенок ксилемы, поскольку в процессе онтогенеза растения по каналам проводящей ткани осуществляется перенос питательных веществ и впитываемой почвенной влаги. По-видимому, появление этой фракции в костре связано с расщеплением пектиновых веществ в периферийных слоях стебля в условиях многодневной росяной мочки льна. Благодаря конденсации влаги в каналах трахеальных элементов ксилемы обеспечивается возможность диффузии водорастворимых продуктов деструкции пектинов с накоплением фракции мигрирующих полиуронидов $\left(\mathrm{P}_{\text {MIGR }}\right)$.

Данные табл. 1 подтверждают предположение, что фракция мигрирующих пектинов является олигомерным продуктом с небольшим числом взаимосвязанных мономерных звеньев. Причем ее количество в субстрате превышает соб- ственное содержание пектинов в клеточной стенке ксилемы.

В наибольшем количестве пектиновые вещества присутствуют в образцах льняной пакли, но среднее значение их молекулярной массы почти в 3 раза меньше, чем для пектинов луба. Повидимому, эти данные отражают успешное решение задач росяной мочки льна по обеспечению эффективной мацерации корового слоя стебля без повреждения волокнистых пучков. Наибольшая степень полимеризации характерна для полиуронидов препарата $\mathrm{P}_{\mathrm{XYL}}$, что связано с особенностями строения ксилемы. Как известно [64], каналы трахеальных элементов в ксилеме сформированы вытянутыми клетками, при отмирании которых образуется сквозная внутренняя полость. Радиальные размеры каналов (15-30 мкм) намного превышают толщину стенок (2-5 мкм), что обусловливает необходимость повышенной длины макромолекулы полиуронидов для скрепления полимерных цепей и уплотнения структуры лигноцеллюлозного комплекса.

Идентификация выделенных препаратов пектина проведена по совокупности характеристических полос колебательных процессов, регистрируемых методом Фурье-ИК-спектроскопии. Спектрограммы, снятые в режиме на пропускание, представлены на рис. 2.

Регистрируемая совокупность основных пиков поглощения соответствует литературным данным о характеристических частотах колебательных процессов для многообразия ковалентных связей в структуре макромолекулы пектиновых веществ [65]:

- $1720 \mathrm{~cm}^{-1}$ - колебания $\mathrm{C}=\mathrm{O}$ связей в неэтерифицированных карбоксильных группах;

- 1420 и 1620 см$^{-1}$ - симметричные и ассиметричные валентные колебания связей карбоксила с ионами металлов $v_{\mathrm{s}}, v_{\mathrm{as}}(\mathrm{C}-\mathrm{OMe})$;

Таблица 1

Массовая доля полиуронидов в исследуемых льноматериалах и результаты вискозиметрического определения степени полимеризации

\begin{tabular}{|c|c|c|c|c|c|c|}
\hline $\begin{array}{l}\text { Льняной } \\
\text { субстрат }\end{array}$ & $\begin{array}{c}\text { Ткань, } \\
\text { содержащая } \\
\text { пектин }\end{array}$ & $\begin{array}{l}\text { Символ } \\
\text { пектина }\end{array}$ & $\begin{array}{c}\text { Содержание } \\
\text { в субстрате, } \\
\text { масс.\%, }\end{array}$ & $\begin{array}{c}\text { Характеристическая } \\
\text { вязкость, } \\
{[\eta], \mathbf{c m}^{3} / \Gamma}\end{array}$ & $\begin{array}{c}\text { Молекулярная } \\
\text { масса, } \\
\bar{M}_{r}, \text { кДа }\end{array}$ & $\begin{array}{c}\text { Степень } \\
\text { полимеризации, } \\
\overline{C I}\end{array}$ \\
\hline \multirow{2}{*}{ костра } & - & $\mathrm{P}_{\text {MIGR }}$ & 4,0 & $1,15 \pm 0,05^{*}$ & $12,9 \pm 0,6^{*}$ & $67 \pm 3^{*}$ \\
\hline & ксилема & $\mathrm{P}_{\mathrm{XYL}}$ & 3,6 & $23,67 \pm 0,29$ & $155,6 \pm 1,9$ & $802 \pm 10$ \\
\hline пакля & паренхима & $\mathrm{P}_{\mathrm{PAR}}$ & 6,3 & $3,07 \pm 0,05$ & $29,1 \pm 0,5$ & $150 \pm 3$ \\
\hline вытряска & луб & $\mathrm{P}_{\text {BAST }}$ & 5,4 & $10,79 \pm 0,45$ & $81,5 \pm 3,4$ & $420 \pm 17$ \\
\hline
\end{tabular}

* для образца $\mathrm{P}_{\mathrm{MIGR}}$ указаны значения показателей для экстрагируемого продукта; для остальных образцов - для индивидуальных макромолекул. 
- $1440 \mathrm{~cm}^{-1}$ - внутренние деформационные ассиметричные колебания метильной группы в карбоксиле $\delta_{\text {as }}\left(\mathrm{O}-\mathrm{CH}_{3}\right)$;

- $1400 \mathrm{~cm}^{-1}$ - валентные колебания С-ОН связи в карбоксиле $v(\mathrm{C}-\mathrm{OH})$;

- 1020-1010 см ${ }^{-1}$ - валентные колебания пиранозных колец $v$ (C-C)(C-O);

- $990 \mathrm{~cm}^{-1}$ - деформационные колебания карбоксила $\delta(\mathrm{C}-\mathrm{OMe})$;

- $920 \mathrm{~cm}^{-1}$ - маятниковые колебания метила в сложноэфирной группировке $\rho\left(\mathrm{O}_{-} \mathrm{CH}_{3}\right)$.

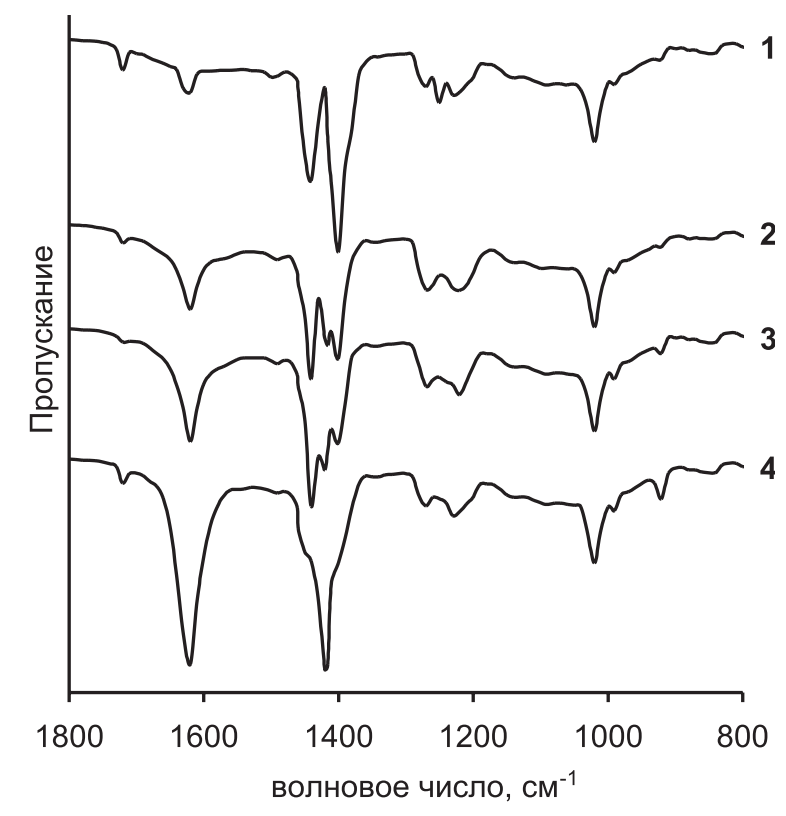

Рис. 2. ИК-спектры пропускания препаратов пектиновых веществ из льняных субстратов:

$$
1-P_{M I G R} ; 2-P_{B A S T} ; 3-P_{P A R} ; 4-P_{X Y L}
$$

Интенсивность основных полос поглощения для выделенных льняных пектинов существенно варьирует. В спектре $\mathrm{P}_{\text {MIGR }}$ наибольшую интенсивность имеют пики при $1400 \mathrm{~cm}^{-1}$ и $1720 \mathrm{~cm}^{-1}$, соответствующие валентным колебаниям неэтерифицированных карбоксильных групп, при существенно меньшей интенсивности колебаний карбоксила в кальций-пектатной форме $\left(1620 \mathrm{~cm}^{-1}\right)$. На спектрограмме $\mathrm{P}_{\mathrm{XYL}}$ напротив наиболее выражен пик полосы $1620 \mathrm{~cm}^{-1}$, характеризующей поглощение пектинатов с ионами кальция.

Вместе с тем спектры пектинов не позволяют количественно охарактеризовать содержание галактуронатных звеньев с различающимся состоянием карбоксильной группы. Это обусловлено невозможностью вычленения полосы колебаний $v(\mathrm{C}-\mathrm{OH})$ и $\delta_{\text {as }}\left(\mathrm{O}-\mathrm{CH}_{3}\right)$ в незамещенном и метоксилированном карбоксиле из сложной суперпозиции накладывающихся колебательных процессов в диапа- зоне частот 1350-1450 см-1. Анализ количества метоксильных групп по максимумам полос поглощения валентных колебаний эфирной связи $v(\mathrm{C}-\mathrm{O}-\mathrm{C})$ 1272 и $1223 \mathrm{~cm}^{-1}$ также не возможен в связи с наложением в этой области полос поглощения деформационных колебаний С-Н связи пиранозных колец и О-Н связи спиртовой гидроксильной группы.

Изолированной полосой является пик ассиметричных валентных колебаний связи С-О в пектате $1620 \mathrm{~cm}^{-1}$. Оценка изменения интенсивности этой полосы валентных колебаний положена в основу используемого метода определения долевого содержания галактуронатных звеньев в незамещенной, метоксилированной и кальций-пектатной формах. Метод реализуется с использованием приема последовательных превращений свободной неэтерифицированной и метоксилированной форм галактуроновой кислоты в пектат кальция с регистрацией увеличения удельного поглощения на частоте $1620 \mathrm{~cm}^{-1}$ методом ИК-спектроскопии полимерных пленок.

В табл. 2 проведено сопоставление исследуемых препаратов пектина по содержанию галактуронатных звеньев с карбоксильными группами в незамещенной $(G H)$, метоксилированной $(G M)$ и кальций-пектатной $(G C)$ формах. Результаты представлены в долевом выражении к общему количеству галактуронатных звеньев.

Как видно, сравниваемые препараты пектина существенно различаются по количеству звеньев $G H$, определяющих хемосорбционный потенциал полиуронидов в отношении положительно заряженных веществ. Обычно при характеристике сорбционной способности пектинов внимание обращают лишь на степень их метоксилирования, поскольку этерификация карбоксилов понижает реакционную способность биополимера, особенно в кислой среде [66]. Замещение ионов кальция в сорбционных процессах возможно только на катионы, обеспечивающие более высокую устойчивость пектинатов [67].

Таблица 2

Результаты анализа химического строения полиуронидных субстратов

\begin{tabular}{cccc}
\hline \multirow{2}{*}{$\begin{array}{c}\text { Образец } \\
\text { пектина }\end{array}$} & \multicolumn{3}{c}{$\begin{array}{c}\text { Долевое содержание форм } \\
\text { галактуронатных звеньев, ед. }\end{array}$} \\
\cline { 2 - 4 } & $\boldsymbol{G H}$ & $\boldsymbol{G M}$ & $\boldsymbol{G C}$ \\
\hline $\mathrm{P}_{\mathrm{MIGR}}$ & 0,50 & 0,44 & 0,06 \\
$\mathrm{P}_{\mathrm{BAST}}$ & 0,30 & 0,55 & 0,15 \\
$\mathrm{P}_{\mathrm{PAR}}$ & 0,22 & 0,58 & 0,20 \\
$\mathrm{P}_{\mathrm{XYL}}$ & 0,27 & 0,37 & 0,36 \\
\hline
\end{tabular}


a)

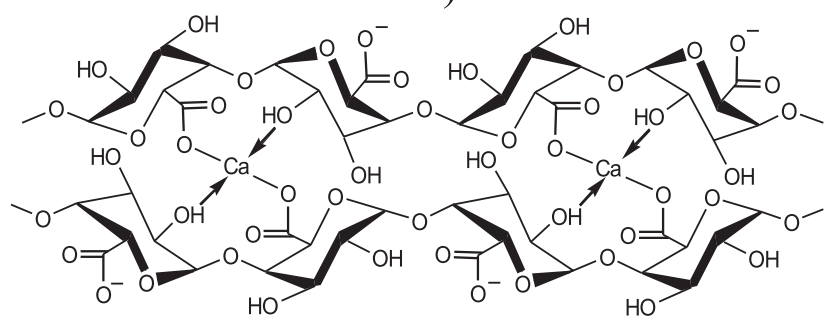

б)

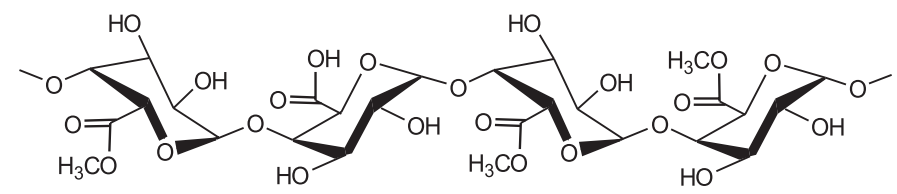

Рис. 3. Схема конформационного образования «еgg-bох» с участием кальций-пектатной формы (а) и фрагмента цепи разветвленных доменов (б) в структуре пектина

В моделируемых нами условиях протекания сорбционных взаимодействий с участием полиуронидов форма $G C$ не является безучастным свидетелем и способна повлиять на хемосорбционную активность субстрата. Нужно учитывать, что после освобождения от клетчатки перевариваемого кормового средства пектины переведены в коллоидное состояние. Как известно, содержание в полимере ионов $\mathrm{Ca}^{2+}$ оказывает определяющее влияние на гелеобразование, структуру и устойчивость пектиновых гелей $[68,69]$.

Звено в кальций-пектатной форме не может появиться в полимерной цепи индивидуально. Обязательно на расстоянии, достаточном для взаимодействия, должно находиться незамещенное звено в другой макромолекуле полиуронида. Сшивка цепей будет устойчивой только при возникновении аналогичных мостиков на соседних звеньях, что приводит к возникновению стабильного конформационного образования «egg-box» («яичная коробка») [70], схема которого представлена на рис. 3а.

С учетом пространственной ориентации глюкопиранозных циклов форма $G C$ может возникнуть только в чередовании с другими разновидностями мономерного звена. Карбоксильная группа в соседних циклах преимущественно должна быть незамещена, что обеспечивает возможность встраивания ионов $\mathrm{Ca}^{2+}$ с любой стороны макромолекулы в зависимости от нахождения близлежащей цепи с комплементарным фрагментом. Это обусловливает возможность образования многослойных структур «egg-box» [71], которая реализуется, по-видимому, лишь при высокой концентрации пектиновых веществ.

Количество повторяющихся сшивок в блоках природных пектинов, как правило, не превышает четырех [72, 73], минимальное число равно двум. Поэтому показанный на рис. $3 б$ вариант соседства одного звена $G H$ с несколькими звеньями $G M$ не предполагает абсорбции иона $\mathrm{Ca}^{2+}$ и отра- жает возможное чередование субъединиц в структуре разветвленных доменов.

Исходя из указанных постулатов проведено моделирование надмолекулярной структуры сравниваемых образцов полиуронидов в соответствии с данными табл. 2. Для образца $\mathrm{P}_{\text {MIGR }}$ в соответствии с условиями экспериментального определения величина $\overline{C \Pi}=67$ (см. табл. 1) является характеристикой не индивидуальной полимерной цепи, а фрагмента структуры, в котором группа макромолекул объединена определенным количеством сшивающих блоков. В данном случае возможен лишь один вариант структурного сочетания звеньев, в котором две олигомерные цепочки соединены одним блоком «egg-box», состоящим из двух ячеек в полном соответствии со схемой на рис. $3 \mathrm{a}$. При этом в четырех ответвлениях суммарно содержится 30 парных повторений $G M-G H$.

Для тканевых пектинов определены следующие статистически вероятные варианты формирования сшивающих блоков и разветвленной части с учетом установленных значений длины полимерной цепочки для индивидуальных макромолекул:

- $\mathrm{P}_{\mathrm{PAR}}-$ с учетом $\overline{C \Pi}=150$ совокуПный состав Звеньев $G H_{33} G M_{87} G C_{30}$ имеет следующее сгруппированное распределение $\left[\left(G C_{2} G H_{2}\right)\right.$ $\left.\left(G M_{7}\right)\right]_{15} G H_{3}$; то есть каждая макромолекула проходит через 15 блоков с двумя звеньями $G C$ в чередовании с двумя звеньями $G H$, блоки разделены ответвлениями из семи звеньев $G M$, в каждом пятом ответвлении одно звено $G H$;

- $\mathrm{P}_{\text {BAST }}-$ при $\overline{C \Pi}=420$ общий состав $G H_{126} G M_{231} G C_{63}$ дает распределение $\left[\left(G C_{3} G H_{3}\right)\right.$ $\left.\left(G M_{11} G H_{3}\right)\right]_{21}$, т.е. макромолекула 21 раз контактирует с соседними цепями в блоках с тремя парами $G C-G H$, а в ответвлениях на одиннадцать звеньев $G M$ приходится три звена $G H$;

- $\mathrm{P}_{\mathrm{XYL}}$ - для $\overline{C \Pi}=792$ состав звеньев $G H_{216} G M_{288} G C_{288}$ дает распределение $\left[\left(G C_{4} G H_{3} G M\right)\right.$ $\left.G M_{3}\right]_{72}$; т.е. каждая макромолекула участвует в 72 блоках с четырьмя звеньями $G C$, между которыми 
a)

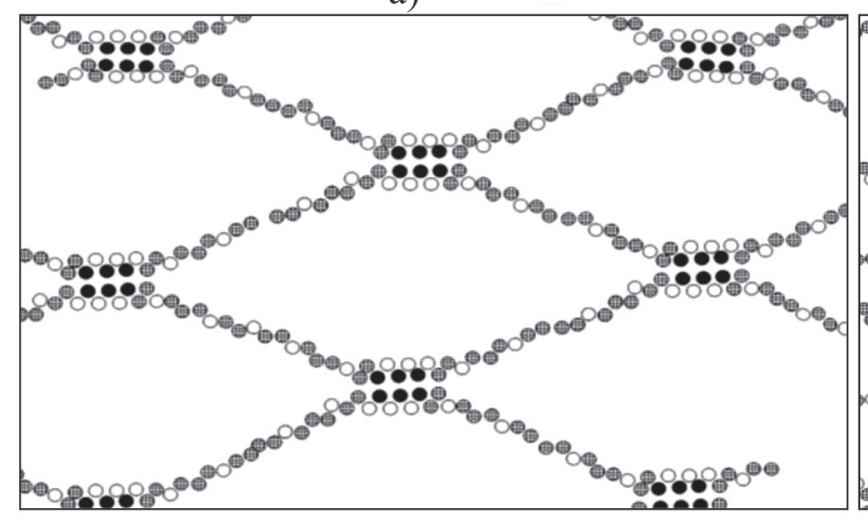

B)

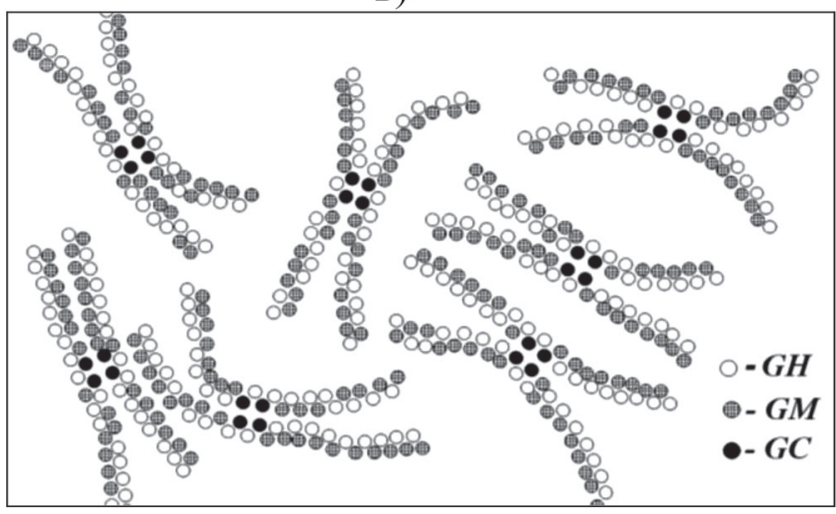

б)

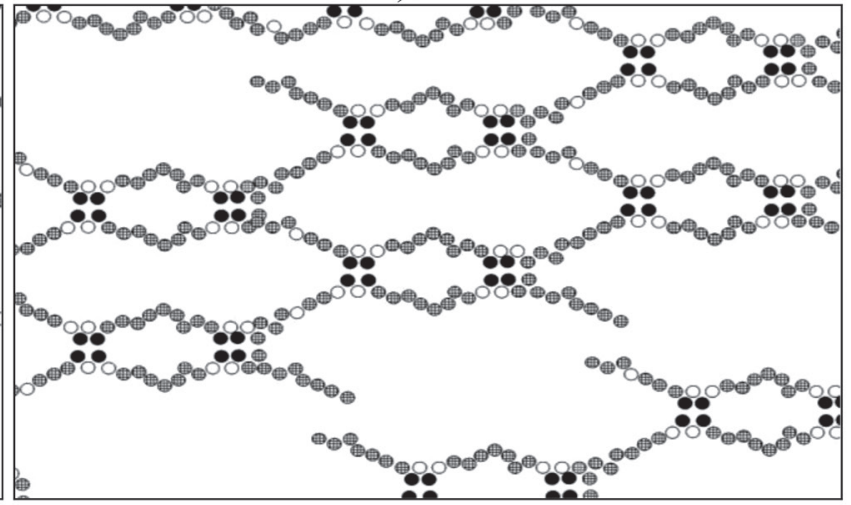

Г)

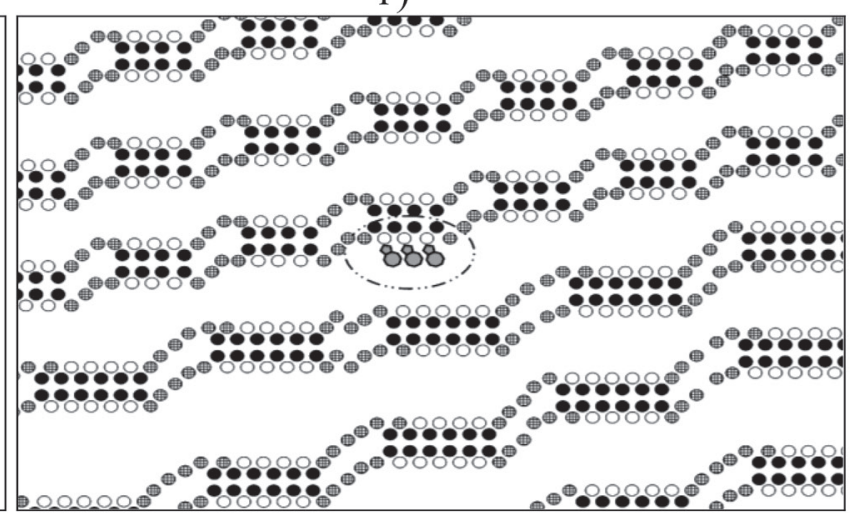

Рис. 4. Модель структурной организации гелей полиуронидов в исследуемых образцах

$$
P_{B A S T}\left(\text { a), } P _ { P A R } \left(\text { (б), } P_{M I G R}(\text { () }) P_{X Y L}\right.\right. \text { (2) : O - GH; ○ - GM; • - GC }
$$

три $G H$ и одно звено $G M$ на краю, а сверхкороткие гибкие сегменты состоят из трех звеньев $G M$. Увеличение длины гибкого сегмента возможно только при условии уменьшения их количества, то есть за счет большего числа звеньев $G C$ в составе формирований «egg-box». Например, для $\overline{C \Pi}=812$ состав звеньев $G H_{216} G M_{312} G C_{288}$ может быть распределен на 48 блоков с шестью звеньями $G C$ : $\left[\left(G C_{6} G H_{6} G M\right) G M_{5}\right]_{24}\left[\left(G C_{6} G H_{4} G M_{2}\right) G M_{5}\right]_{24}$. Но и в таком варианте ответвления содержат лишь пять звеньев $G M$.

Взаимное расположение цепей в исследуемых образцах полиуронидов представлено на рис. 4.

При построении моделей сделан ряд допущений. Прежде всего, это касается двумерного представления взаимосвязей макромолекулярных цепей, упрощающего фактическую 3d-организацию полимерных сеток. Такой вариант можно рассматривать, как фрагмент одного сетчатого слоя, из которого макромолекулы могут переходить в соседние параллельные слои. Для упрощения количество звеньев $G C$ в сшивающих блоках принято неизменным и кратным экспериментальному значению содержания данной формы в полимере. Пропорционально распределено и число мономерных звеньев в гибких сегментах между уплотнениями. Очевидно, колебания этих параметров возможны, но они уравновешивают друг друга. Схемы отражают статистически усредненное распределение структурных элементов пектина в растительных тканях. И, наконец, в принятом варианте полимерные структуры сформированы макромолекулами гомогалактуронана. Для реальных пектиновых веществ схемы должны быть дополнены включением 2-4 \% $\alpha$-рамнозных остатков [74]. Боковые ответвления от звеньев рамнозы будут ориентированы в ортогональном направлении, в параллель с расположением целлюлозных фибрилл и гемицеллюлоз, поэтому они не оказывают влияния на формирование сшитой сетчатой структуры.

Представленные схемы позволяют визуализировать различие объектов, скрадывающееся за численной информацией о соотношении форм галактуронатных звеньев (табл. 2). Становится понятно, что с ростом содержания формы $G C$ пропорционально удваивается суммарное количество звеньев, задействованных в блоках с высокоплотной кристаллической структурой. При этом спутником $G C$, как правило, является звено $G H$. Симбатно сокращается длина гибких сегментов, что повлияет 
на набухание полимера в воде и плотность образующихся гидрогелей.

Наибольшие размеры разветвленных доменов в образце $\mathrm{P}_{\text {BAST }}$ обусловливают отмечаемые специалистами гиперэластичные свойства гелей, образуемых пектинами льняного волокна [75]. Различия в организации сетчатых структур по сравнению с препаратом $\mathrm{P}_{\text {PAR }}$ вполне закономерны, поскольку в лубе макромолекулам полиуронидов приходится огибать и скреплять фибриллы целлюлозы и лигноуглеводные образования с относительно крупными поперечными размерами. В тонкостенных клетках паренхимы пектиновые вещества объединяют в углевод-белковые комплексы менее толстые пучки из упорядоченных гемицеллюлозных макромолекул.

Очевидно, что после деструктирующего воздействия микроорганизмов в условиях росяной мочки льна структура пектинов корового слоя существенно дефрагментирована. Это иллюстрируют разрывы между разветвленными доменами препарата $\mathrm{P}_{\mathrm{PAR}}$ на рис. 4б. Вполне логично, что выпавшими фрагментами из целостной картинки сетчатых формирований являются укороченные остатки $\mathrm{P}_{\text {MIGR }}$, представленные на рис. 4в. Высокая плотность звеньев $G H$ в ответвлениях $\mathrm{P}_{\text {MIGR }}$ обусловливает комплементарность участка для разрыва глюкозидной связи под действием пектиназ в процессах росяной мочки льна, а также формирование гидратной оболочки, обеспечивающей диффузионное перераспределение продуктов ферментации вглубь стебля.

На рис. 4в показаны оба варианта компоновки сшивающих блоков препарата $\mathrm{P}_{\mathrm{XYL}}$. Как видно, варьирование количества сгруппированных звеньев $G C$ не вносит принципиальных изменений в характер расположения полимерных цепей. Высокоупорядоченная структура препарата $\mathrm{P}_{\mathrm{XYL}}$ обусловлена высокой плотностью вещества в клеточных стенках ксилемы. Это связано с отличительными особенностями морфологии льняного стебля. В его структуре отсутствуют древесинные волокна (либриформ), которые обеспечивают необходимый уровень прочности тканям в разновидностях древесных растений. Поэтому в отличие от большинства травянистых растений ксилема льна выполняет не только проводящие, но и механические функции. С целью обеспечения достаточного уровня прочности стеблю льна-долгунца генетически предопределена аномально высокая степень лигнификации ксилемы $[76,77]$. Стенки трахеальных элементов пронизаны и скованы спиралевидными образованиями лигнина. Показанное на рис. 4г ступенчатое смещение сшивающих блоков отражает возможность полиуронидов следовать за спиралью лигнина. При этом лентовидная парная группировка полимерных цепей, по-видимому, более оправдана, чем создание сетчатых структур с переходами макромолекул из одного разветвленного домена в другой. Этому способствуют малая длина гибкого сегмента и взаимно упорядоченное расположение участков с благоприятным сочетанием мономерных звеньев для образования множественных межцепных сшивок в двух соседних макромолекулах, биосинтез которых проходит совместно в процессе роста клетки ксилемы. В этом случае пектиновые вещества максимально способны обеспечивать наряду с лигнином повышение прочности клеточных стенок ксилемы, оплетая и уплотняя продольно расположенные целлюлозные фибриллы.

После деструкции нейтральных полисахаридов в процессе выделения пектинов из льняного сырья сетчатая структура полиуронидов сохраняется не только в получаемых модельных препаратах. В таком же виде пектины высвобождаются в пищеварительном тракте жвачных животных и могут принимать участие в протекающих абсорбционных процессах. Из данных рис. 4 следует, что у всех сравниваемых образцов пектина нет принципиальных ограничений для 100 \%-ного участия галактуронатных звеньев $G H$ во взаимодействиях с молекулами теофиллина, моделирующего связывание токсичных алкалоидов. Даже звенья, участвующие в формировании блоков «eggbох», сохраняют способность для хемосорбционного связывания молекулы теофиллина, что на рис. 4в отражают символы, обведенные штрихпунктирной овальной линией.

Действительно, как показано на рис. 5а, молекулы теофиллина не испытывают стерических ограничений для взаимодействия с ионизированными карбоксильными группами в каждом спаренном повторении полиуронидных звеньев, фиксируя при этом свое положение водородной связью с вторичным гидроксилом в соседнем галактуронатном звене.

Естественным регулятором этого процесса является степень диссоциации карбоксильных групп, которая, с одной стороны, определяет количество реакционноспособных группировок, а с другой стороны, влияет на плотность гидратной оболочки вокруг полимерной цепи. В связи с этим оптимум кислотности в процессах связывания катионных сорбатов у разных исследователей [78-83] сильно варьирует в зависимости от плотности заряда на поверхности сорбируемой частицы и вида пектинового субстрата.

При подавлении диссоциации незамещенных карбоксильных групп в сильнокислой среде аб- 
a)

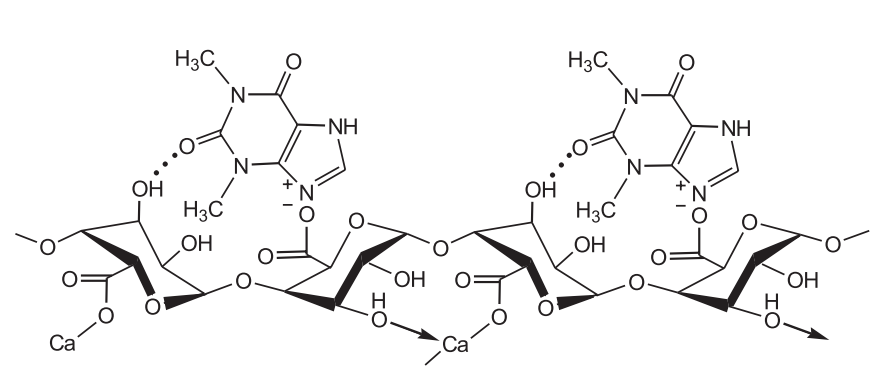

б)

Рис. 5. Схемы абсорбционного взаимодействия молекулы теофиллина с полиуронидом в умеренно кислой (а) и сильнокислой (б) средах

сорбция теофиллина, по-видимому, также возможна за счет образования водородных связей по схеме, представленной на рис. 5б. Такие взаимодействия могут протекать, в частности, при пребывании перевариваемой биомассы в основном желудке жвачных животных, где уровень $\mathrm{pH}$ составлет от 1,5 до 2,5 ед. Очевидно, что такая форма связывания будет непрочной и обратимой, но это может стимулировать стадию внешней диффузии сорбата и облегчить более прочное связывание при повышении величины $\mathrm{pH}$ в зоне двенадцатиперстной кишки.

Естественным препятствием для связывания алкалоидов в сильнокислой среде может стать сближение участков пространственной сетки полиуронидов с возникновением множественных водородных связей непосредственно между недиссоциированными карбоксильными группами в зве- ньях соседних цепей. В связи с эти представляет интерес исследование влияния структурной организации сетчатых доменов на сорбционную способность сравниваемых образцов полиуронидов не только для умеренно- и слабокислых сред, но и в сильнокислых растворах.

\section{Закономерности абсорбции теофиллина пектинами льна}

\section{Влияние кислотности средь}

В исследуемых системах необходимо учитывать многофакторное влияние уровня кислотности на состояние компонентов и характер протекающих взаимодействий. На рис. 6 сопоставлены значения двухчасовой сорбции модельного алкалоида пектиновыми препаратами в буферных a)

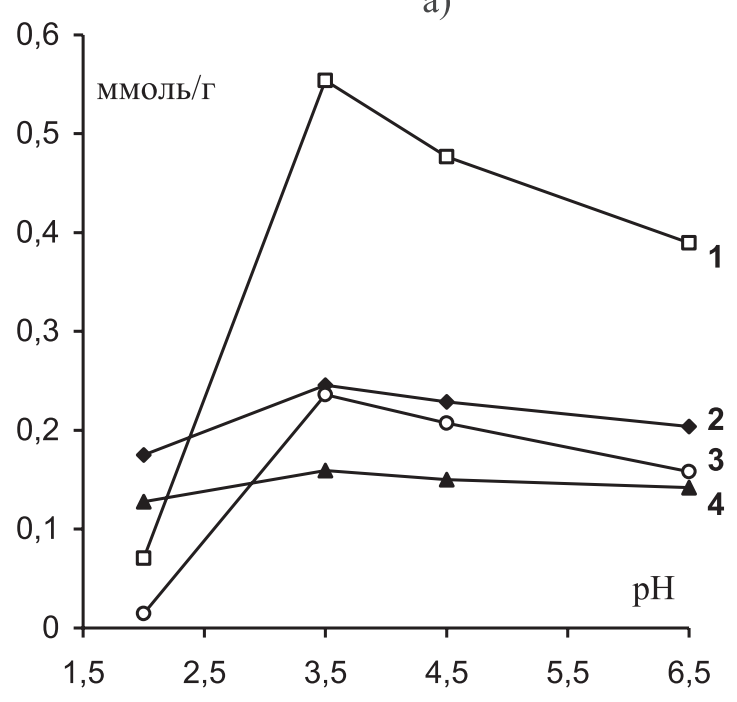

б)

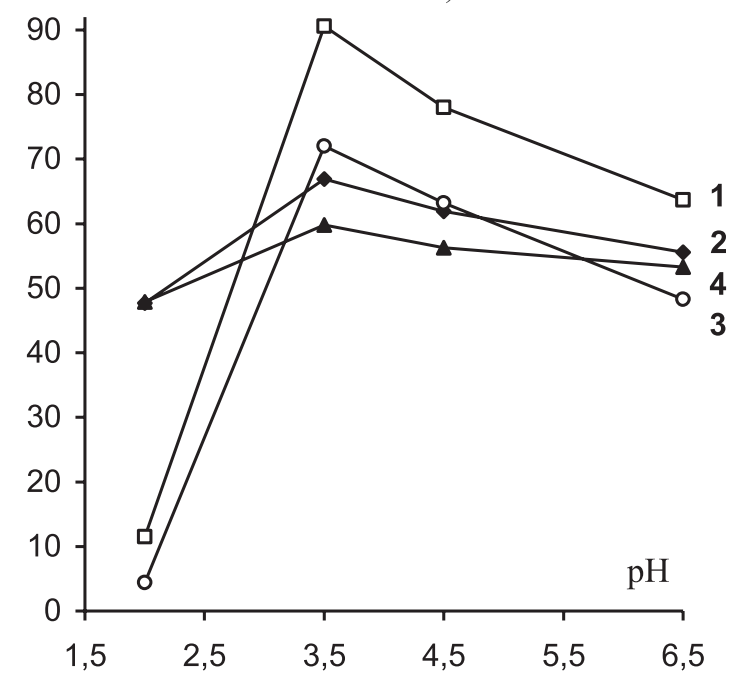

Рис. 6. Влияние рН на сорбцию теофиллина препаратами пектина при $40{ }^{\circ} \mathrm{C}$ за 120 мин (a) и относительную реализацию сорбционного потенциала субстратов (б):

$$
1-P_{M I G R} ; 2-P_{B A S T} ; 3-P_{X Y L} ; 4-P_{P A R}
$$


системах с уровнем рН от 2,0 до 6,5 ед. при температуре $40{ }^{\circ} \mathrm{C}$.

Наибольший уровень сорбционной активности препараты демонстрируют при $\mathrm{pH} 3,5$. Диссоциация карбоксильных группировок в пектине и протонирование гетероатома в имидазольном цикле теофиллина создают условия для самопроизвольного протекания хемосорбционных взаимодействий. Наблюдаемое в этих условиях приращение сорбции при последовательных переходах от $\mathrm{P}_{\text {PAR }}$ к $\mathrm{P}_{\text {MIGR }}$ (см. рис. 6а) пропорционально увеличению долевого содержания галактуронатных звеньев в форме $G H$ (см. табл. 2):

$$
\Delta \mathrm{q}=1,4147 \cdot G H, \mathrm{R}^{2}=0,993 .
$$

Если расчетный уровень сорбционного потенциала субстратов $\mathrm{Q}_{\max }$ определять из возможностей связывания молекул теофиллина всей совокупностью незамещенных карбоксильных групп в отношении 1:1, то диаграмма на рис. 6 может отражать полноту использования внутренних возможностей сравниваемых субстратов. В такой интерпретации видно, что достигаемая степень сорбции $\left(q_{120} / Q_{\max }\right)$ определяется не только количеством сорбционных центров, но и их доступностью.

Правомерно полагать, что даже в условиях максимально проявляемой эффективности при pH 3,5 не все карбоксильные группы в звеньях $G H$ диссоциированы. При этом в одинаковых условиях константа диссоциации должна иметь равное значение для всех образцов пектина. Следовательно, для сорбционных взаимодействий имеются препятствия, которые наиболее сильно проявляются для субстратов $\mathrm{P}_{\mathrm{PAR}}$ и $\mathrm{P}_{\mathrm{BAST}}$.

Сопоставление результатов с нашими модельными представлениями о структуре гидрогелей пектина (см. рис. 4) позволяет сделать предположение, что повышенное сопротивление для встраивания теофиллина в сетчатую структуру препаратов $\mathrm{P}_{\text {PAR }}$ и $\mathrm{P}_{\text {BAST }}$ может быть связано с экранированием адсорбционных центров под влиянием многочисленного окружения из соседних метоксилированных звеньев со специфическим структурированием молекул воды в оболочке гидрофобногидратируемой метильной группировки. Основанием для гипотезы является удовлетворительная корреляция между показателем степени реализации сорбционного потенциала при $\mathrm{pH}$ 3,5 и величины соотношения в полиуронидах мономерных звеньев в формах $G H$ и $G M$ :

$$
\frac{\mathrm{q}_{120(\mathrm{pH} 3,5)}}{\mathrm{Q}_{\max }}=40,241+44,156 \frac{\mathrm{GH}}{\mathrm{GM}}, R^{2}=0,9939
$$

Показательно, что свободный член уравнения практически совпадает с величиной показателя $q_{120} / Q_{\max }$ для препаратов $\mathrm{P}_{\text {РAR }}$ и $\mathrm{P}_{\text {ВАST }}$ при $\mathrm{pH} 2$. Равенство поглотительной способности этих субстратов в сильнокислой среде согласуется с представлениями об одинаковой доступности звеньев $G H$ в их сетчатой структуре для взаимодействия с теофиллином по схеме, представленной на рис. 5б. Удаленное расположение макромолекул в разветвленных доменах в данном случае проявляется как позитивный фактор, препятствующий взаимной ориентации участков с незамещенными звеньями и ассоциации цепей с образованием водородных связей между атомами карбоксильных группировок:

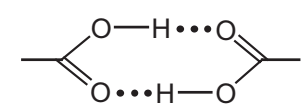

Схемы на рис. 4в и 4г демонстрируют структурную предрасположенность гидрогелей $\mathrm{P}_{\text {MIGR }}$ и $\mathrm{P}_{\mathrm{XYL}}$ к самоассоциации в сильнокислой среде, что должно ухудшить их способность к связыванию теофиллина. Обвальное сокращение сорбции этими препаратами при $\mathrm{pH} 2$ демонстрирует правильность предположений о поведении субстратов, правомерность выбранного подхода к описанию системы и выявлению рычагов для управления процессами.

С повышением рН до 4,5 и 6,5 ед. константа ионизации карбоксилов снижаться не может. Тем не менее, для всех препаратов на графиках (рис. 6) наблюдаются спадающие ветви. Темпы снижения сорбции прогрессируют в ряду: $\mathrm{P}_{\mathrm{PAR}} \rightarrow \mathrm{P}_{\mathrm{BAST}} \rightarrow \mathrm{P}_{\mathrm{XYL}}$ $\rightarrow \mathrm{P}_{\text {MIGR }}$. В той же последовательности увеличивается количество звеньев $G H$, встроенных в сегменты многократного их чередования с другими мономерными формами. Для тканевых пектинов такими сегментами являются участки цепей в сшивающих блоках. В препарате $\mathrm{P}_{\text {MIGR }}$ весь олигомерный отрезок цепи подпадает под этот критерий, но наиболее ответственной зоной являются ответвления от ячеек «egg-box».

Специфика таких сегментов связана с уплотнением гидратной оболочки вокруг ионизированного карбоксила. При наличии нескольких диссоциированных звеньев $G H$ в соседних структурных ячейках гидратные оболочки карбоксилов воздействуют друг на друга и дополнительно уплотняются. В связи с этим появление в сегменте новой диссоциированной группы может удлинить (объединить) зоны уплотненного гидратного окружения полимера, создающего препятствие для взаимодействия теофиллина с сорбционным центром. 
Количество звеньев $N$ в сегментах с регулярным чередованием формы $G H$ в исследуемых образцах пектинов возрастает в ряду: $\mathrm{P}_{\mathrm{PAR}}-4, \mathrm{P}_{\text {ВАST }}-6$, $\mathrm{P}_{\mathrm{XYL}}-8$ (или 12), $\mathrm{P}_{\mathrm{MIGR}}-17$. Динамика изменений показателя $N$ коррелирует с уменьшением величины $q_{120} / Q_{\max }$ при повышении рН с 3,5 до 4,5 ед. Причем сравнение корреляционных соотношений для альтернативных вариантов формирования структуры «egg-box» в пектине $\mathrm{P}_{\mathrm{XYL}}$ позволяет отдать предпочтение более удлиненной форме блоков с шестью сшивками, поскольку в этом случае достигается полная линеаризация результатов:

$$
\begin{aligned}
& \qquad N\left(\mathrm{P}_{\mathrm{XYL}}\right)=8 ; \\
& \frac{\mathrm{q}_{120(\mathrm{pH} 3,5)}-\mathrm{q}_{120(\mathrm{pH} 4,5)}}{\mathrm{Q}_{\max }}=1,541+0,678 \cdot N, R^{2}=0,9094 \\
& \bullet N\left(\mathrm{P}_{\mathrm{XYL}}\right)=12 ; \\
& \frac{\mathrm{q}_{120(\mathrm{pH} 3,5)}-\mathrm{q}_{120(\mathrm{pH} 4,5)}}{\mathrm{Q}_{\max }}=0,748+0,69 \cdot N, R^{2}=0,9984 .
\end{aligned}
$$

Таким образом, с учетом параметра кислотности кормовой массы в двенадцатиперстной кишке жвачных животных можно полагать, что в реальных условиях не удастся обеспечить оптимальный режим сорбционного связывания азагетероциклических микотоксинов пектиновыми веществами льняного компонента кормовых добавок. Снижение на 6-13\% от уровня реализации сорбционного потенциала пектинов при $\mathrm{pH}$ 3,5 может быть обусловлено структурными особенностями ближ- него гидратного окружения сорбционных центров. С учетом полученных результатов анализ кинетических зависимостей и выявление ключевых механизмов сорбции теофиллина гидрогелевыми препаратами пектинов целесообразно начать с первичного разграничения внутри- и внешнедиффузионного лимитирования в хемосорбционном процессе.

Анализ диффузионных моделей переноса теофеллина в коллоидной системе пектинов льна

Сорбционные эксперименты выполнены с применением высокоразбавленных $(0,1 \%)$ растворов пектиновых препаратов, что сопоставимо с реальным уровнем концентрации пектинов в объеме перевариваемой кормовой биомассы. После растворения в воде порошковых субстратов $\mathrm{P}_{\text {PAR }}, \mathrm{P}_{\text {BAST }}$ и $\mathrm{P}_{\mathrm{XYL}}$ и предварительной их выдержки в течение двадцати минут образуются микрогетерогенные системы, представляющие собой взвесь набухших частиц, структура которых сохраняется благодаря многочисленным сшивкам полимерных цепей. В растворах $\mathrm{P}_{\text {MIGR }}$ методом динамического светового рассеяния также регистрируется наличие дисперсной фазы с размером частиц 35-40 нм. Следовательно, также как и в случаях с твердофазными сорбентами, процесс массопереноса следует подразделять на внешнюю диффузию к поверхности частиц и внутреннюю диффузию в структуре набухшего полиуронида.

На рис. 7 представлены экспериментальные кинетические кривые сорбции теофиллина при $\mathrm{pH} 4,5$ и их графическая интерпретация в рамках диффу-
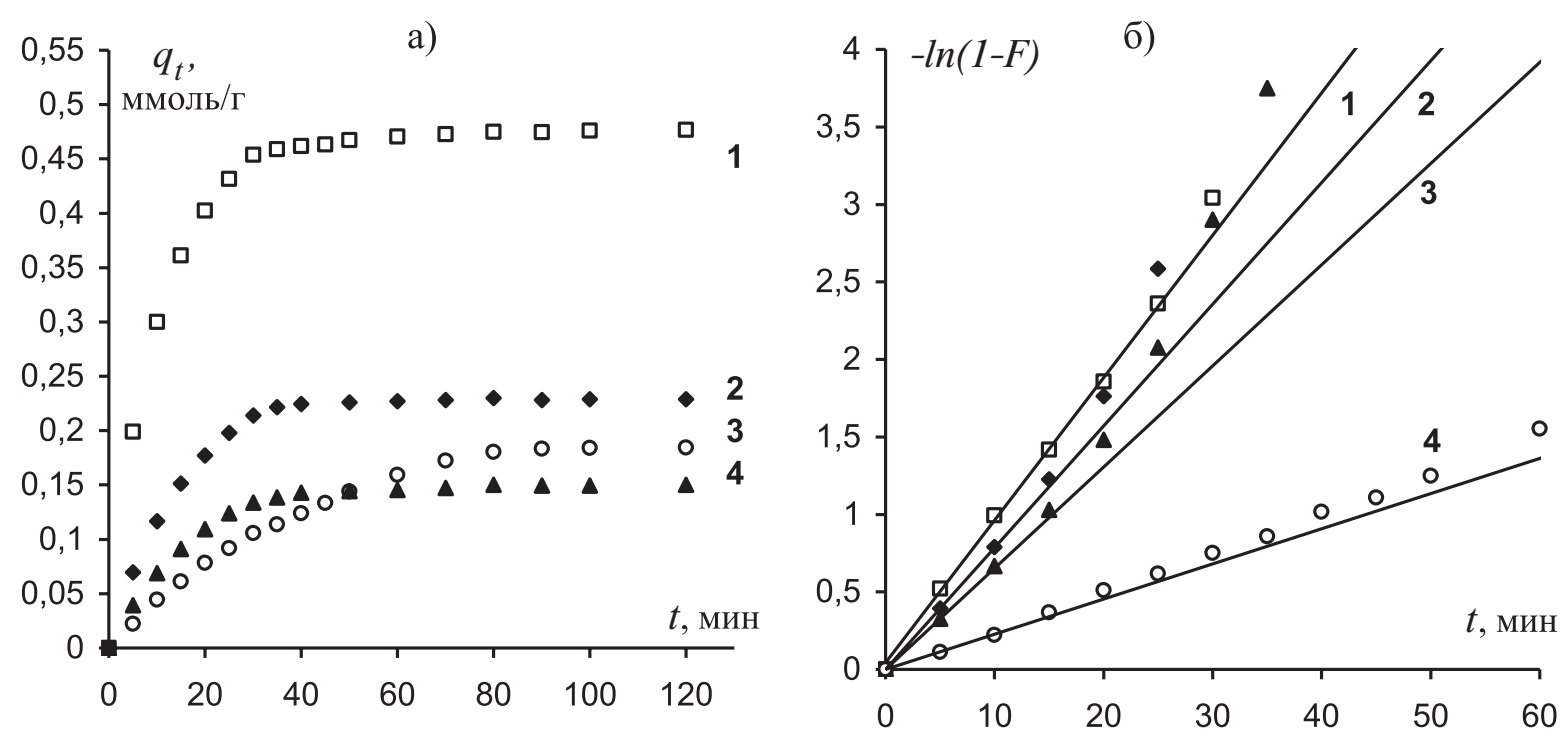

Рис. 7. Экспериментальные зависимости сорбционного поглощения теофиллина препаратами пектина при рН 4,5 (а) и их анализ в координатах диффузионной модели Бойда (б):

$$
1-P_{M I G R} ; 2-P_{B A S T} ; 3-P_{X Y L} ; 4-P_{P A R}
$$


зионной модели Бойда, применяемой для характеристики вариантов лимитирования сорбционных процессов стадией внешнедиффузионного массопереноса $[58,84]$. В этом случае динамика изменения текущих значений количества связанного сорбата $q_{\mathrm{t}}$ должна линеаризоваться в координатах $\lg (1-F)$ от $t$, где $t$ - время, $F$ - степень достижения равновесия в системе, рассчитываемая из соотношения текущего и равновесного значений сорбции: $F=\left(q_{\mathrm{t}} / q_{\mathrm{e}}\right)$.

Преобразования Бойда адекватно описывают эмпирические данные лишь при обеспечении требуемого уровня коэффициента детерминации $\left(\mathrm{R}^{2}>0,9\right)$, но соблюдение этого условия нередко демонстрируют, охватывая участки затухающей сорбции и сорбционного равновесия [85]. Представленные на рис. 76 результаты для исследуемых систем свидетельствуют, что на участках интенсивной сорбции экспериментальные значения (точки) достаточно быстро отклоняются от векторов, объединяющих первые группы значений с началом координат и отражающих влияние внешней диффузии. Для структурированных тканевых пектинов внешнедиффузионное торможение проявляется лишь в течение первых 10 мин, когда связывание сорбата происходит на относительно доступных адсорбционных центрах. В дальнейшем сорбционный процесс не зависит от диффузионного восполнения сорбата в приповерхностном слое раствора. По-видимому, закономерно, что зависимость сорбции от подвижности теофиллина во внешней среде имеет более выраженное проявление для образца $\mathrm{P}_{\text {MIGR }}$. Но и в этой системе корреляция нарушается спустя 20 мин после начала сорбции, когда в связывании сорбата начинают участвовать менее доступные галактуронатные звенья, прилегающие к блоку межцепной сшивки (см. рис. 4в).

На рис. 8 сгруппированы результаты анализа кинетических зависимостей с применением моделей, учитывающих внутридиффузионный механизм лимитирования сорбционного процесса. Классическая модель Морриса-Вебера рассматривается многими специалистами как вариант мультилинейного описания массопереноса со смешанно диффузионным режимом лимитирующих стадий $[86,87]$. Характеристику внутридиффузионного лимитирования дает линеаризация эмпирических данных на участке со степенью насыщения субстрата $F$ более 0,5 . На рис. 8а показаны варианты членения результатов на две линеаризуемые области, которые позволяют, по мнению [88], сопоставить кинетические характеристики стадий внешней и внутренней диффузии по величине константы скорости диффузии $k_{D}$ (ммоль $\left.\Gamma^{-1} \mathrm{Mин}^{-0,5}\right)$, входящей в уравнение модели Морриса-Вебера:

$$
q_{t}=k_{D} \cdot t^{0,5}+C .
$$

Величина $k_{D}$ определяется с учетом тангенса угла наклона соответствующего участка и достигаемого в эксперименте значения равновесной сорбции $q_{e}$.

Применение модели гелевой диффузии дает возможность определения кинетических параметров массопереноса, входящих в уравнение Бойда a)

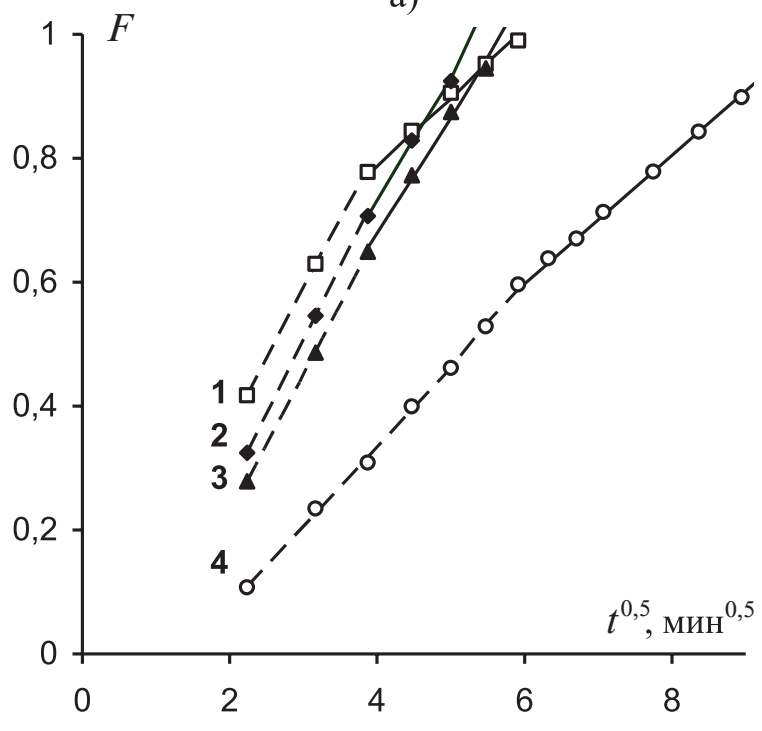

б)

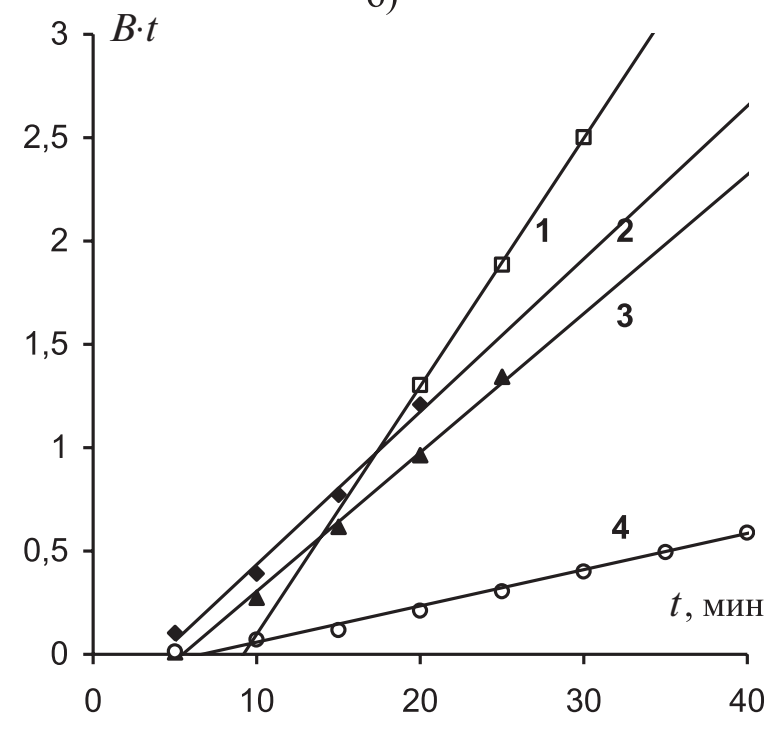

Рис. 8. Интерпретация кинетики сорбции теофиллина образцами пектинов в координатах модели Морриса-Вебера (а) и модели гелевой диффузии (б):

$$
1-P_{\text {MIGR }} ; 2-P_{B A S T} ; 3-P_{\text {PAR }} ; 4-P_{X Y L}
$$


для внутридиффузионного лимитирования сорбции [60]:

$$
F=1-\frac{6}{\pi^{2}} \sum_{n=1}^{\infty}\left(1 / n^{2}\right) \exp \left(-D \pi^{2} n^{2} r^{-2} t\right),
$$

где $D \pi^{2} r^{-2}=B-$ кинетический коэффициент, $\mathrm{c}^{-1}$; $D$ - эффективный коэффициент диффузии, $\mathrm{m}^{2} \mathrm{c}^{-1}$; $r$ - средний радиус зерна сорбента, м; $n$ - натуральные числа от 1 до бесконечности.

Построение представленных на рис. 86 зависимостей $B \times t=f(t)$ осуществляется путем преобразования соотношения $F=f(t)$ с использованием справочных данных для определения величины произведения $B \times t$ [89]. Для препарата $\mathrm{P}_{\text {MIGR }}$ анализ проведен для временного интервала 20-30 мин, на котором наблюдали (см. рис. 8а) резкое замедление сорбции при достижении степени насыщения субстрата $F$ более 0,75 . Для тканевых пектинов результаты на рис. 86 удовлетворительно описываются линейными функциями во всем временном диапазоне, что подтверждает адекватность оценки внутридиффузионного лимитирования в рамках данной модели и позволяет, исходя из угла наклона аппроксимирующей зависимости, определить значения характеристических показателей кинетического коэффициента $B$ и эффективного коэффициента внутренней диффузии $D$.

Результаты анализа данных рис. 8 суммированы в табл. 3 и позволяют количественно сопоставить влияние структурной организации пектиновых веществ на специфику диффузионного переноса сорбируемого теофиллина.

Заметим, что константа $k_{D l}$ не является абсолютной характеристикой диффузионной подвижности сорбата в растворителе, поскольку ее величина зависит также и от кинетических параметров хемосорбционного взаимодействия с субстратом. Сопоставлять следует константы $k_{D I}$ и $k_{D 2}$ между собой (характер взаимодействия с адсорбционными центрами одинаков), а также величину соотно- шения констант для разных субстратов. Для группы тканевых пектинов величина относительного показателя примерно одинакова $(1,23-1,26)$. Для $\mathrm{P}_{\text {MIGR }}$ соотношение констант возросло до 2,04, что свидетельствует одновременно об отсутствии препятствий для поддержания градиента концентрации сорбата в поверхностном слое и о повышенном сопротивлении для протекания внутридиффузионных процессов.

Соотношение констант $k_{D 1}$ и $k_{D 2}$ может существенно измениться при переходе к реальным процессам в пищеварительном тракте животных, когда внешней средой является густая масса перевариваемой кормовой смеси. Моделирование массопереноса в приближенных условиях составит предмет последующих исследований. Вместе с тем очевидно, что внешние примеси не меняют состояние набухшего зерна пектиновых сорбентов и динамику внутреннего массопереноса, интенсивность которого определяется особенностями химического строения и надмолекулярной структуры биополимера.

Полученные значения эффективного коэффициента диффузии позволяют количественно охарактеризовать зависимость лимитирующей стадии массопереноса в объеме гидратированных частиц пектина от особенностей структурной организации полиуронидов, проиллюстрированных на рис. 4. Наибольшей проницаемостью обладают частицы препарата $\mathrm{P}_{\text {BAST }}$ с ажурной сетчатой надмолекулярной структурой. Уменьшение размера ячейки сетчатых доменов в частицах препарата $\mathrm{P}_{\mathrm{PAR}}$ закономерно проявляется в снижении коэффициента $D$ в 4,5 раза.

Снижение на порядок коэффициента диффузии $D$ теофиллина для препарата $\mathrm{P}_{\mathrm{XYL}}$ свидетельствует, что ленточные образования спаренных макромолекул после освобождения от лигноцеллюлозного армирования формируются в клубки. Повышенная уплотненность клубка, по-видимому,

Кинетические параметры применяемых диффузионных моделей сорбции теофиллина

Таблица 3 пектиновыми препаратами при $40{ }^{\circ} \mathrm{C}$ и рН 4,5

\begin{tabular}{|c|c|c|c|c|}
\hline \multirow{3}{*}{ Пектин } & \multirow{2}{*}{\multicolumn{2}{|c|}{$\begin{array}{c}\text { Модель Морриса-Вебера } \\
\begin{array}{c}\text { константа скорости диффузии, } \\
\text { ммоль } \cdot \Gamma^{-1} \text { мин }^{-0,5}\end{array}\end{array}$}} & \multicolumn{2}{|c|}{ Модель гелевой диффузии } \\
\hline & & & \multirow{2}{*}{$\begin{array}{c}\text { кинетический } \\
\text { коэффициент, } \\
B \cdot 10^{3}, \mathrm{c}^{-1}\end{array}$} & \multirow{2}{*}{$\begin{array}{c}\text { эффективный } \\
\text { коэффициент диффузии, } \\
D \cdot 10^{11}, \mathbf{M}^{2} \mathrm{c}^{-1}\end{array}$} \\
\hline & $k_{D I}$ & $k_{D 2}$ & & \\
\hline $\mathrm{P}_{\mathrm{XYL}}$ & 0,0267 & 0,0217 & 0,292 & 0,266 \\
\hline $\mathrm{P}_{\mathrm{PAR}}$ & 0,0322 & 0,0261 & 1,120 & 1,022 \\
\hline $\mathrm{P}_{\mathrm{BAST}}$ & 0,0511 & 0,0406 & 1,233 & 4,500 \\
\hline $\mathrm{P}_{\text {MIGR }}$ & 0,0939 & 0,0461 & 1,942 & 0,0000279 \\
\hline
\end{tabular}


обусловливает полное отсутствие зон собственной структуры воды и сильное структурирование ее молекул в зонах ближней и дальней гидратации полимерных цепей, что осложняет перемещение теофиллина в объеме частицы. В ячеистой структуре $\mathrm{P}_{\mathrm{PAR}}$ и особенно $\mathrm{P}_{\text {BAST }}$ свободная вода, по-видимому, присутствует, а ее количество коррелирует с размером ячеек.

В таком случае снижение эффективного коэффициента диффузии $D$ для препарата $\mathrm{P}_{\text {MIGR }}$ на 4 десятичных порядка относительно значений для $\mathrm{P}_{\mathrm{XYL}}$ можно связать только с увеличением толщины и плотности зоны ближней гидратации ответвлений с высоким содержанием незамещенных мономерных звеньев и диссоциирующих карбоксильных групп. Проявление гидратации таких участков рассматривалось при анализе влияния кислотности среды на результаты равновесной сорбции теофиллина. Согласно схеме на рис. 4в зонами повышенного диффузионного сопротивления являются участки гибких сегментов с наиболее близким расположением незамещенных звеньев, которые непосредственно примыкают к сшивке «еggbox». Сверхнизкое значение коэффициента внутренней диффузии объясняет резкое замедление сорбции при достижении 75 \%-ного насыщения полимера.

Позитивным моментом является то, что внутренняя диффузия не контролирует начальный этап сорбционного процесса, на котором обеспечивается основной вклад в достижение наивысшего уровня сорбционной способности препарата $\mathrm{P}_{\text {MIGR }}$ в сравнении с эффективностью использования тканевых пектинов льна.

\section{Анализ кинетических моделей сорбиии теофиллина}

Практические задачи описания кинетики стационарного сорбционного процесса включают оценку констант, отражающих изменение динамики по мере подхода системы к равновесию, а также определение расчетного значения предельной емкости $q_{e}^{*}$ и степени приближения к нему в условиях эксперимента. Для анализа эмпирических данных использованы кинетические модели псевдопервого порядка Лагергрена и псевдо-второго порядка Хо и Маккея [61-63]. Оба варианта описания предполагают, что взаимодействие сорбируемого вещества с адсорбционными центрами лимитирует процесс сорбции. В первом случае моделирование охватывает обширный круг процессов, в которых диффузия предшествует сорбции. Второй вариант корректно описывает процессы с протекани- ем химического взаимодействия между сорбатом и функциональными группами сорбента.

Применимость моделей определяется возможностью линейной аппроксимации кинетических зависимостей корреляционными соотношениями следующего вида:

- модель псевдо-первого порядка:

$$
\ln \left(q_{e}-q_{t}\right)=\ln q_{e}^{*}-k_{1} t
$$

- модель псевдо-второго порядка:

$$
t / q_{t}=1 /\left(k_{2} q_{e}^{* 2}\right)+t / q_{e}^{*},
$$

где $k_{1}$ - константа скорости адсорбции псевдо-первого порядка, мин ${ }^{-1} ; k_{2}-$ константа скорости адсорбции псевдо-второго порядка, г·ммоль ${ }^{-1}$ мин $^{-1}$.

Адекватность описания эмпирических данных принято демонстрировать графически в координатах $\ln \left(q_{\mathrm{e}}-q_{\mathrm{t}}\right)$ от $t$ для модели Лагергрена и в координатах $t / q_{\mathrm{t}}$ от $t$ для модели Хо и Маккея. В первом случае величина константы $k_{1}$ рассчитывается по углу наклона аппроксимирующей зависимости, а расчетное значение предельной сорбции материала $q_{\mathrm{e}}^{*}$ определяется экстраполяцией на начальный момент сорбционного процесса. Во втором варианте расчет значений показателя $q_{\mathrm{e}}{ }^{*}$ осуществляется по тангенсу угла наклона линейной зависимости, а исходя из величины свободного члена определяют параметр $k_{2}$.

Для исследуемых систем линейная графическая интерпретация кинетического участка сорбционных зависимостей при $\mathrm{pH}$ 4,5 и 6,5 получена в координатах модели псевдо-второго порядка, а для сильнокислой среды $\mathrm{pH} 2$ - в координатах модели псевдо-первого порядка. Корректность использования соответствующих моделей продемонстрирована на рис. 9 на примере препаратов $\mathrm{P}_{\text {MIGR }}$ и $\mathrm{P}_{\mathrm{BAST}}$, для которых одновременно показаны результаты описания процесса по модели Лагергрена (штриховые линии $1_{4,5} *, 3_{4,5} *$ и $1_{6,5} * 3_{6,5} *$ соответственно для $\mathrm{pH}$ 4,5 и 6,5 ед.) и по модели псевдо-второго порядка (сплошные линии $1_{4,5}{ }^{* *}, 3_{4,5} * *$ и $\left.1_{6,5} * *, 3_{6,5} * *\right)$.

Представленные результаты наглядно демонстрируют, что поглощение теофиллина пектиновыми субстратами точно воспроизводится сплошными линиями для модели псевдо-второго порядка во всех случаях, когда уровень кислотности предполагает хемосорбционный механизм связывания собрата на функциональных центрах полимера. Сорбционные процессы с участием неионизированных в сильнокислой среде пектиновых 
a)

б)

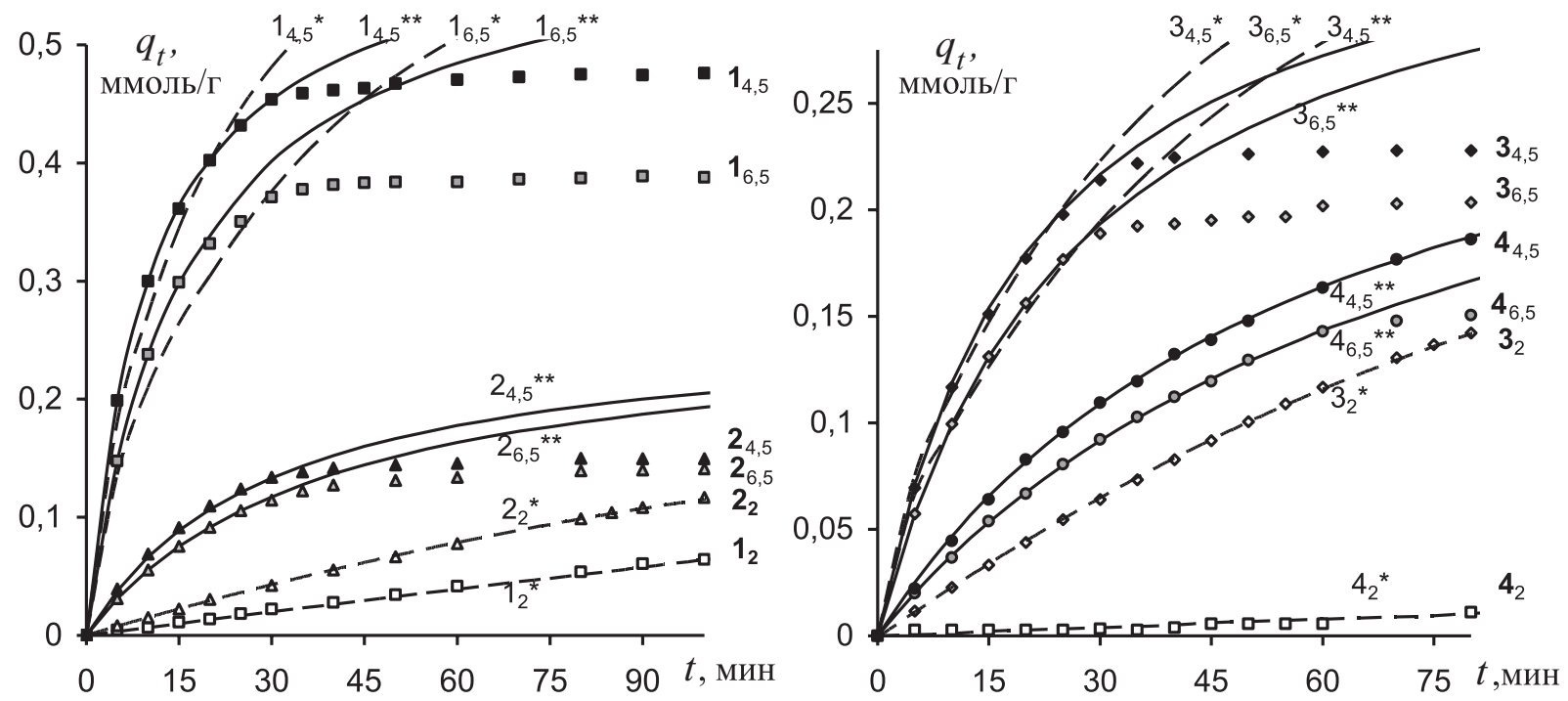

Рис. 9. Кинетика сорбции теофиллина (точки) пектиновыми препаратами $P_{\text {MIGR }}$ и $P_{\mathrm{PAR}}(\mathbf{a}), \mathbf{P}_{\mathrm{BAST}}$ и $\mathbf{P}_{\mathrm{XYL}}$ (б) и аппроксимирующие зависимости (линии) с применением кинетических моделей:

$1_{2}, 1_{4,5}$ и $1_{6,5}-P_{\text {MIGR }}$ при рH 2, 4,5 и 6,5 соответственно; $2_{2}, 2_{4,5}, 2_{6,5}-P_{P A R} ; 3_{2}, 3_{4,5}, 3_{6,5}-P_{B A S T} ; 4_{2}, 4_{4,5}, 4_{6,5}-P_{X Y L}$;

$1_{p H} *-4_{p H}^{*}$ - зависимости по кинетической модели псевдо-первого порядка;

$1_{p H}^{* *}-4_{p н}^{* *}$ - зависимости по кинетической модели псевдо-второго порядка

препаратов лучше описываются в рамках модели Лагергрена (см. штриховые линии).

Из совокупности представленных в табл. 4 расчетных кинетических характеристик сорбционного процесса, прежде всего, следует обратить внимание на величину показателя $q_{\mathrm{e}}$ *. Для каждого субстрата независимо от условий поглощения теофиллина и вида корректно (с учетом $\mathrm{pH}$ ) применяемой кинетической модели воспроизводится одинаковое значение предельной сорбции. Причем эти значения очень близки к характеристике сорбционного потенциала субстратов $\mathrm{Q}_{\max }$, использованного при анализе рис. 6 и определяемого с учетом долевого содержания в полимере звеньев $G H$.

Поскольку доступность незамещенных галактуронатных звеньев в существенной степени за- висит от их совместного структурного распределения с метоксилированными и кальций-пектатными мономерными единицами, логично по результатам физико-химических исследований получить обоснованные значения предельной сорбции $q_{e}^{*}$, уступающие величине теоретически возможного сорбционного потенциала $\mathrm{Q}_{\max }$. В результате корреляционного анализа взаимосвязи между предельной сорбционной емкостью пектиновых субстратов и их химическим строением получено следующее многопараметровое соотношение:

$q_{e}^{*}=0,887+1,0889 \cdot G H-0,1222 \cdot G C-a \cdot G M, \mathrm{r}=0,9775$.

Коэффициент а равен 0,0417 или 0,03 соответственно для низкометоксилированных пектинов

Таблица 4

Кинетические параметры сорбции теофиллина пектиновыми препаратами

\begin{tabular}{|c|c|c|c|c|c|c|}
\hline \multirow{3}{*}{ Препарат } & \multicolumn{4}{|c|}{ Модель псевдо-второго порядка } & \multirow{2}{*}{\multicolumn{2}{|c|}{$\begin{array}{c}\text { Модель псевдо-первого порядка } \\
\text { рH 2,0 }\end{array}$}} \\
\hline & \multicolumn{2}{|c|}{ pH 4,5 } & \multicolumn{2}{|c|}{ pH 6,5 } & & \\
\hline & $\begin{array}{c}k_{2}, \\
\text { г·ммоль } \\
\text { мйн }^{-1}\end{array}$ & $\begin{array}{c}q_{e}^{*}, \\
\text { ммоль/г }\end{array}$ & $\begin{array}{c}k_{2}, \\
\text { г·ммоль } \\
{ }^{-1} \mathbf{M и н ~}^{-1}\end{array}$ & $\begin{array}{c}q_{e}^{*}, \\
\text { ммоль/г }\end{array}$ & $\begin{array}{c}k_{l}, \\
\text { мин }^{-1}\end{array}$ & $\begin{array}{c}q_{e}^{*}, \\
\text { ммоль/г }\end{array}$ \\
\hline $\mathrm{P}_{\mathrm{XYL}}$ & 0,051 & 0,326 & 0,039 & 0,326 & 0,0004 & 0,325 \\
\hline $\mathrm{P}_{\mathrm{PAR}}$ & 0,125 & 0,266 & 0,098 & 0,264 & 0,0058 & 0,268 \\
\hline $\mathrm{P}_{\mathrm{BAST}}$ & 0,131 & 0,366 & 0,101 & 0,365 & 0,0064 & 0,367 \\
\hline $\mathrm{P}_{\text {MIGR }}$ & 0,158 & 0,609 & 0,104 & 0,608 & 0,0011 & 0,612 \\
\hline
\end{tabular}


$\left(G M<0,5 ; \mathrm{P}_{\text {ХYL }}\right.$ и $\left.\mathrm{P}_{\text {MIGR }}\right)$ или высокометоксилированных препаратов $\left(G M>0,5 ; \mathrm{P}_{\mathrm{BAST}}\right.$ и $\left.\mathrm{P}_{\mathrm{PAR}}\right)$.

Регрессионная модель может быть использована для прогнозирования профилактического действия пектинсодержащих сорбентов в отношении алкалоидов на основании данных о соотношении в полиуронидах галактуронатных звеньев в незамещенной, метоксилированной и кальций-пектатной формах. Полученные значения констант скорости адсорбции и предельной сорбционной емкости позволяют определить дозировку пектинсодержащих кормовых добавок для предупреждения микотоксикозов из расчета удельного связывания алкалоидов в течение 30-минутного прохождения перевариваемой кормовой массы в двенадцатиперстной кишке жвачных животных на основании интегрального уравнения адсорбционной модели псевдо-второго порядка:

$$
q_{30}=30 /\left(\frac{1}{k_{2} q_{\mathrm{e}}^{* 2}}+\frac{30}{q_{\mathrm{e}}^{*}}\right)
$$

Важно отметить, что процесс сорбции алкалоидов не заканчивается при перемещении кормовой смеси в тонкий кишечник и может с небольшой потерей в скорости продолжаться в присутствии желчно-панкреатического сока с рН 6,8. Для тканевых пектинов константа $k_{2}$ снижается одинаково $(1,27-$ 1,29 раза). Для препарата $\mathrm{P}_{\text {MIGR }}$ падение более существенно - в 1,51 раза, но величина показателя продолжает быть наибольшей для сравниваемых субстратов.

В комментарии к полученным значениям константы внешней диффузии $k_{D I}$ (см. табл. 3) отмечалось, что в реальных системах подвижность сорбата может быть затруднена в связи с повышенной вязкостью среды. Представленные в табл. 4 параметры сорбционного процесса при рН 2 позволяют предполагать, что при использовании препаратов $\mathrm{P}_{\text {BAST }} \mathrm{P}_{\text {PAR }}$ эта проблема может быть в существенной степени устранена благодаря связыванию теофиллина в сильнокислой среде желудка жвачных животных по механизму физической адсорбции (см. рис. 5б). Предварительное накопление сорбата в набухшем зерне пектина в течение двухчасового пребывания корма в желудке обеспечит ускоренное протекание хемосорбционных взаимодействий при переходе кормовой массы в кишечник.

\section{Закономерности абсорбиии теофиллина} композищияли пектинов льна и монтмориллонита

Эффективность действия пектиновых субстратов сопоставлена с результатами сорбции теофиллина монтмориллонитом (Мт) - разновидностью алюмосиликатных сорбентов, широко применяемых для профилактики микотоксикоза животных.

В сильнокислой среде Мт практически не проявляет сорбционных свойств в отношении теофиллина и, как показано на рис. 10а, наращивает сорбционную активность по мере снижения кислотности. Сопоставление результатов с данными рис. 6а показывает, что при рН 4,5 (основное значении для связывания микотоксинов в пищеварительном тракте животных) Мт лишь на 11,5 \% превосходит величину показателя $q_{120}$ для препарата $\mathrm{P}_{\mathrm{PAR}}$. Препараты $\mathrm{P}_{\mathrm{XYL}}$ и $\mathrm{P}_{\mathrm{BAST}}$ эффективнее на 10 и 30 \%, а препарат $\mathrm{P}_{\text {MIGR }}$ превосходит сорбционные свойства образца сравнения почти в 3 раза.

Сравнение по величине константы скорости сорбции не представляется возможным, поскольку при рН 4,5 процессы с участием пектиновых субстратов и Мт описываются разными кинетическими моделями. Для Мт лучшую адекватность описания обеспечивает модель псевдо-первого порядка, что демонстрирует точное совпадение эмпирических данных с ходом расчетных кривых $1 *$ и $2 *$ При повышении рН с 4,5 до 6,5 ед. константа скорости сорбции $k_{1}$ растет с 0,0303 до 0,0418 мин $^{-1}$. Визуальное сопоставление с нарастанием показателя $q_{t}$ для полиуронидов на рис. 7а свидетельствует, что активность Мт сопоставима лишь с наименее скоростной сорбцией для препарата $\mathrm{P}_{\mathrm{XYL}}$. Рacчетный уровень предельной сорбции Мт составляет 0,1944 и 0,2028 ммоль/г при рН 4,5 и 6,5 соответственно. Это в 1,3-3 раза уступает величине показателя $q_{e}^{*}$ для пектиновых препаратов.

$\mathrm{C}$ учетом нарастающего внимания к вопросам создания гибридных полимер-неорганических сорбентов на основе алюмосиликатов модифицированных полиэлектролитами [90-93], проведена оценка эффективности связывания алкалоидов бинарными препаратами пектинов льна и монтмориллонита. В обзоре [94] представлен критический анализ существующих методов и механизмов эксфолиации слоистых алюмосиликатов для достижения целевых эффектов развития внутренней поверхности минерального наполнителя и придания специфических функций создаваемым нанокомпозитам. Применяемый в работе твердофазный метод получения органо-минеральных систем [56] предполагает окружение микрогранул пектина частицами набухшего в воде Мт и позволяет регулировать степень интеркаляции полимерных цепей пектина в межплоскостные пространства алюмосиликата в зависимости от степени сшивки макромолекул звеньями $G C$.

По результатам исследований сорбции теофиллина выявлены различия в поведении модельных препаратов на основе пектинов льняного сы- 
a)

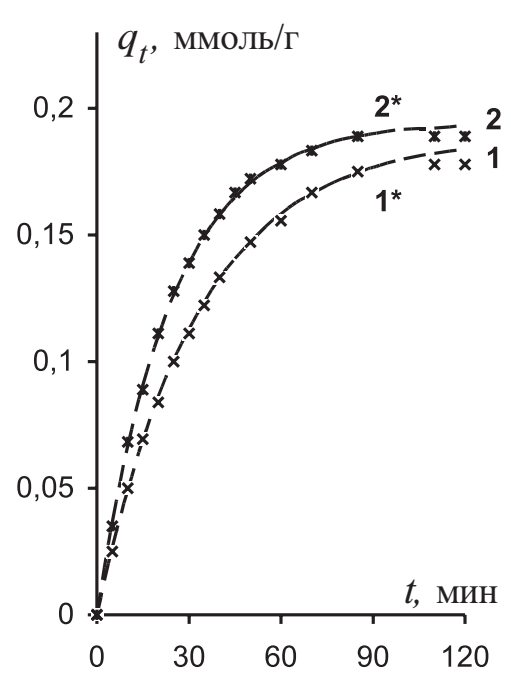

б)

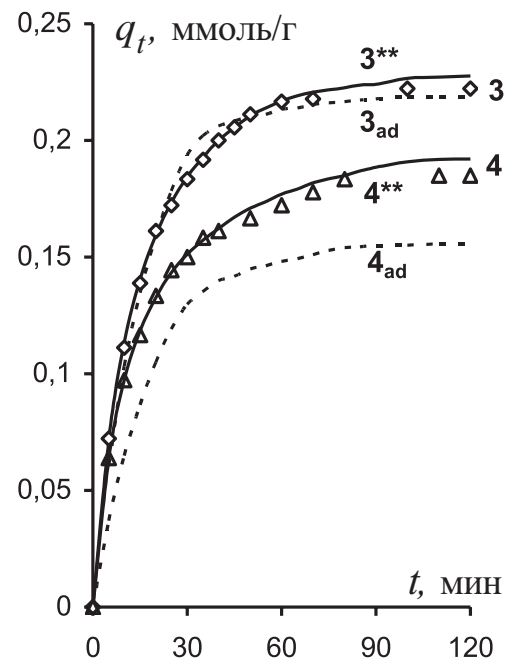

B)

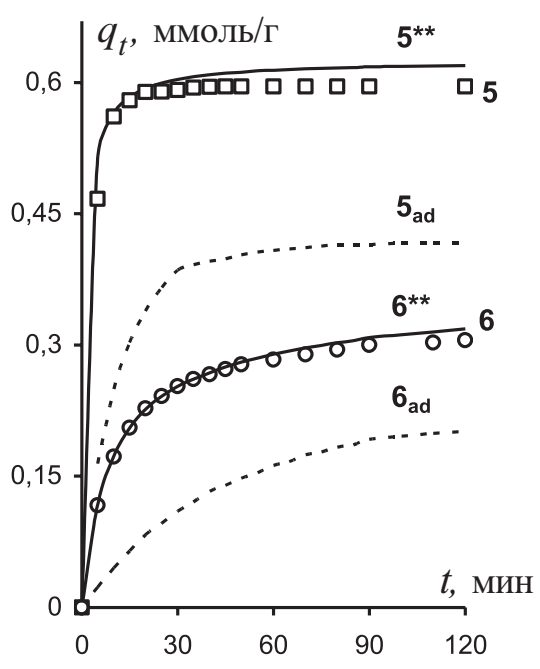

Рис. 10. Кинетика сорбции теофиллина монтмориллонитом (а) и бинарными препаратами монтмориллонита с пектинами (б) и (в) в соотношении 20:80

1 и 2 - эмпирические данные (точки) соответственно при рН 4,5 и 6,5;

1 * и 2*-расчетные зависимости по модели псевдо-первого порядка (штриховая линия);

3, 4, 5 и 6-эмпирические данные для образиов $P_{\text {BAST }}-M m, P_{P A R}-M m, P_{\text {MIGR }}-M m$ и $P_{P A R}-M m$ при pH 4,5;

$3^{* *}, 4^{* *}, 5^{* *}$ и $6^{* *}$ - расчетные зависимости по модели псевдо-второго порядка (сплошная линия);

$3_{a d^{p}} 4_{a d}, 5_{a d}$ и $6_{a d}$ - расчетные зависимости аддитивного вклада компонентов (пунктир)

рья. В случае образца $\mathrm{P}_{\text {BAST }}$-Мт (рис. 10б) расчетная кривая аддитивного вклада (кр. 3 ad ) компонентов, присутствующих в препарате с процентным соотношением 80:20, практически совпадает с динамикой нарастания эмпирических результатов (точки 3). Следовательно, частицы пектина не обладают способностью к внедрению в межслоевые пространства Мт. Компоненты бинарного препарата присутствуют в системе и проявляют свои сорбционные свойства независимо друг от друга. А совокупный результат действия смеси немного уступает сорбционной способности $\mathrm{P}_{\mathrm{BAST}}$ при индивидуальном применении.

В противоположность этому результаты сорбции образцом $\mathrm{P}_{\mathrm{PAR}}-\mathrm{MT}$ (точки 4) значительно опережают кривую аддитивного проявления активности компонентов (кр. $4_{\text {ad }}$ ). Причину указанных различий нужно искать в особенностях структуры препаратов пектина, проиллюстрированных на рис. 4. По-видимому, индифферентность $\mathrm{P}_{\text {BAST }}$ к присутствию Мт в меньшей степени связана с более крупным размером ячейки сетчатых дометов. Более важным обстоятельством является целостность и неповрежденность сетчатой структуры в объеме частиц $\mathrm{P}_{\text {BAST }}$ в отличие от пектина паренхимных тканей стебля, подвергнутых микробиологической деструкции в процессах росяной мочки льна. На рис. 4 показано наличие в структуре $\mathrm{P}_{\text {PAR }}$ концевых сегментов, которые способны проникать в межслоевые пространства слоистого силиката, обеспечивая его эксфолиацию. Небольшие размеры концевых ответвлений ограничивают глубину интеркаляции, предупреждая тем самым существенное блокирование внутренней поверхности Мт.

Вопреки опасениям компоненты бинарной системы $\mathrm{P}_{\mathrm{XYL}}-\mathrm{MT}$ также проявили способность к взаимодействию в условиях получения композиции. Причем ленточные образования спаренных макромолекул $\mathrm{P}_{\mathrm{XYL}}$ обеспечивают более эффективную эксфолиацию Мт по сравнению с влиянием немногочисленных и, что важно, более тонких концевых ответвлений в структуре $\mathrm{P}_{\mathrm{PAR}}$. Для композита $\mathrm{P}_{\mathrm{XYL}}-\mathrm{MT}$ зафиксирован максимум относительного проявления супераддитивности: достигаемая величина равновесной сорбции в 1,5 раза превышает аддитивный показатель (кр. $\left.6_{\text {ad }}\right)$. Особенно важно, что прирост 30-минутной сорбции $\left(q_{30}\right)$ над аддитивным значением достигает 2,3 раза, в то время как для препаратов $\mathrm{P}_{\mathrm{MIGR}}-\mathrm{MT}_{\text {и }} \mathrm{P}_{\mathrm{PAR}}-\mathrm{MT}$ различие составляет 1,53 и 1,39 раза.

В абсолютном выражении максимальный эффект супераддитивности демонстрирует система $\mathrm{P}_{\mathrm{MIGR}}-$ Мт. Важно не только, что прирост равновесной сорбции (точки 5) над аддитивным показателем (кр. 5 ad превышает, например, расчетную величину сорбционной емкости компонентов $\mathrm{P}_{\mathrm{PAR}}-\mathrm{MT}$ по кр. $4_{\text {ad }}$. Показательны рекордно большие различия на начальных участках зави- 
симостей 5 и $5_{\text {ad }}$ : прирост величины $q_{10}$ составляет 0,311 ммоль/г, что составляет половину от равновесного значения. Синергизм в развитии сорбционной способности препарата $\mathrm{P}_{\text {MIGR }}-\mathrm{MT}$, повидимому, обеспечивают оба компонента.

Благодаря проиллюстрированному на рис. 4в электростатическому отталкиванию ответвлений с встречно направленным расположением диссоциированных карбоксильных групп, в процессе интеркаляции частиц $\mathrm{P}_{\text {MIGR }}$ в структуру Мт обеспечивается максимальное увеличение межплоскостного расстояния в слоистом алюмосиликате. При этом пространство между слоями Мт является своеобразным концентратором, повышающим содержание сорбата во внешней среде для пектинового компонента, что интенсифицирует хемосорбционное связывание теофиллина на адсорбционных центрах $\mathrm{P}_{\text {MIGR }}$.

Кинетика сорбции теофиллина бинарными препаратами адекватно описывается в рамках модели Хо и Маккея, о чем свидетельствует ход расчетных зависимостей $3^{* *}-6^{* *}$. Кинетические характеристики процессов сопоставлены в табл. 5 .

Таблица 5

Кинетические параметры сорбции теофиллина пектин-монтмориллонитными препаратами при рН 4,5

\begin{tabular}{lccc}
\hline Сорбент & $\begin{array}{c}\boldsymbol{k}_{2}, \\
\text { г・ммоль }\end{array}{ }^{-1}$ мин $^{-1}$ & $\frac{\boldsymbol{k}_{\mathbf{2}} \text { (композит) }}{\boldsymbol{k}_{\mathbf{2}} \text { (пектин) }}$ & $\begin{array}{c}\boldsymbol{q}_{e}{ }^{*}, \\
\text { ммоль/г }\end{array}$ \\
\hline $\mathrm{P}_{\mathrm{XYL}}-\mathrm{MT}$ & 0,340 & 6,7 & 0,328 \\
$\mathrm{P}_{\mathrm{PAR}}-\mathrm{MT}$ & 0,422 & 3,4 & 0,272 \\
$\mathrm{P}_{\mathrm{BAST}}-\mathrm{MT}$ & 0,272 & 2,1 & 0,339 \\
$\mathrm{P}_{\mathrm{MIGR}}-\mathrm{MT}$ & 1,494 & 9,5 & 0,625 \\
\hline
\end{tabular}

Для удобства сравнения значения константы $k_{2}$ представлены не только для исследуемых бинарных композиций, но и в относительном выражении к величине показателя для базового пектинового препарата (см. табл. 4). Как видно, прежний аутсайдер $\left(\mathrm{P}_{\mathrm{XYL}}\right)$ существенно добавил в скоростном режиме абсорбции и по величине $k_{2}$ превосходит вице-лидера в рейтинге пектиновых субстратов $\left(\mathrm{P}_{\text {BAST }}\right)$. Примечательно, что присутствие Мт все-таки оказывает влияние на свойства препарата $\mathrm{P}_{\text {BAST }}$, проявляющееся в двукратном повышении константы $k_{2}$. Очевидно, адгезия частиц Мт на поверхности зерна $\mathrm{P}_{\text {BAST }}$ обеспечивает отмеченный для системы $\mathrm{P}_{\text {MIGR }}-\mathrm{MT}$ эффект повышения градиента концентрации теофиллина в поверхностном слое, что способствует ускорению хемосорбционных взаимодействий в структуре зерна.
Показателен рост константы $k_{2}$ для композита на основе $\mathrm{P}_{\text {MIGR }}$, хоть это и не сопровождается ощутимым повышением предельной сорбции для $\mathrm{P}_{\text {MIGR }}-$ Мт. В данной системе степень реализации сорбционного потенциала реализуется почти на $100 \%$ и в 3,2 раза превышает величину $q_{e}^{*}$ при индивидуальном применении Мт. Полученные результаты обосновывают целесообразность использования водорастворимой фракции полиуронидов в льняной костре для создания специализированных гибридных средств профилактики микротоксикоза животных и человека. Параметры $k_{2}$ и $q_{e}{ }^{*}$ для $\mathrm{P}_{\text {MIGR }}-$ Мт позволяют по уравнению кинетической модели адсорбции псевдо-второго порядка определить дозировку суточного потребления высокоэффективного композиционного сорбента.

Таким образом, выявленные закономерности влияния химического строения пектиновых веществ на их сорбционные свойства в отношении теофиллина позволяют регламентировать вид вторичных продуктов льнопереработки, применяемых для получения льносодержащих кормовых добавок, оценить эффективность их применения для связывания азагетероциклических микотоксинов и научно обосновать нормы потребления сорбентов для профилактики микотоксикоза жвачных животных.

\section{Выводы}

1. Методами ИК-спектроскопии и вискозиметрии оценено различие пектиновых веществ, содержащихся в тканях паренхимы, луба и древесины вторичных продуктов льнопереработки. По данным долевого соотношения галактуронатных звеньев с незамещенной карбоксильной группой, а также в метоксилированной и кальций-пектатной формах проведено моделирование надмолекулярной структуры выделенных препаратов тканевых пектинов, а также водорастворимой фракции полиуронидов, экстрагируемых из льняной костры.

2. Методом стационарной сорбции из ограниченного объема исследовано поглощение теофиллина препаратами пектинов из разбавленных водных растворов при температуре $40{ }^{\circ} \mathrm{C}$ и варьируемом значении $\mathrm{pH} 2,0 ; 3,5 ; 4,5$ и 6,5 . Выявлены корреляции между значениями равновесной сорбции теофиллина и параметрами надмолекулярной структуры пектинового зерна.

3. Анализ сорбционных кривых с применением диффузионных моделей Бойда и Морриса-Вебера выявил смешанно диффузионный режим протекания массопереноса при $\mathrm{pH} 4,5$, позволил определить длительность начальной стадии сорбции, 
осложненной внешней диффузией, и сопоставить значения константы скорости диффузии для стадий внешне- и внутридиффузионного лимитирования. С применением модели гелевой диффузии определены значения эффективного коэффициента диффузии теофиллина в объеме гидратированных частиц пектина, изменение которых согласуется с представлениями о формировании надмолекулярной структуры полиуронидов и специфике гидратационного окружения разных форм галактуронатных звеньев.

4. Обосновано применение кинетической моделей Лагергрена для описания сорбции теофиллина при $\mathrm{pH} 2,0$ и кинетической модели Хо и Маккея при протекании сорбционного процесса в растворах с $\mathrm{pH} 4,5$ и 6,5. Определены значения показателя предельной сорбции $q_{e}{ }^{*}$ для сравниваемых полиуронидных субстратов и получена корреляционная модель для прогнозирования предельной сорбционной емкости пектиновых сорбентов в отношении алкалоидов на основании данных о долевом соотношении форм галактуронатных звеньев. Практическая ценность полученных данных о величине константы скорости адсорбции $k_{2}$ и показателя $q_{e}{ }^{*}$ связана с возможностью обоснования дозировки кормовых добавок, содержащих разные виды пектинсодержащих льняных материалов, для предупреждения микотоксикоза жвачных животных, провоцируемых многочисленными видами азагетероциклических микотоксинов.

5. Показано превосходство пектиновых препаратов по сравнению с монтмориллонитом - разновидностью широко применяемых алюмосиликатных сорбентов. Исследована сорбция теофиллина бинарными препаратами пектин-монтмориллонит в соотношении 80:20. Различия в проявляемых эффектах супераддитивной сорбционной способности композитов связаны с особенностями надмолекулярной структуры пектинов и возможностями регулируемой интеркаляции полимерных цепей в структуру слоистого минерала.

Исследования выполнены в рамках Государственного задания Института химии растворов им. Г.А. Крестова РАН (проект №01201260483) с использованием приборной базы ЦКП «Верхне-волжский региональный иентр физико-химических исследований».

\section{Литература}

1. Khorshidi S., Karkhaneh A., Bonakdar S., Omidian M.M. J. Appl. Polym. Sci. 2019. V. 137. N 28. P. 48859. doi 10.1002/app.48859.
2. Ghorbani M., Roshangar L., Rad J.S. European Polymer J. 2020. V. 130. P. 109697. doi 10.1016/j.eurpolymj.2020.109697.

3. Sathya U., Nithya M., Keerthi P. Chemical Physics Letters. 2020. V. 744. P. 137201. doi 10.1016/j. cplett.2020.137201.

4. Yunlong J., Bodo F. Composites Communications. 2020. V. 18. P. 5-12. doi 10.1016/j.coco.2019.12.010

5. Chabbert B., Padovani J., Djemiel C., Ossemond J., Lemaitre A., Yoshinaga A., Hawkins S., Grec S., Beaugrand J., Kurek B. Industrial Crops and Products. 2020. V. 148. P. 112255. doi 10.1016/j.indcrop.2020.112255.

6. Niwinska B. Digestion in Ruminants. In book: Carbohydrates - Comprehensive Studies on Glycobiology and Glycotechnolo, Edition: 1, Chapter: 11, Publisher: CC BY, Editors: Chang Ch.-F. 2012. P. 245-258. doi 10.5772/51574.

7. Beigh Y.A., Ganai A.M., Ahmad H.A. Vet. World. 2017. V. 10. N 4. P. 424-437. doi 10.14202 / vetworld.2017.424-437.

8. Kelzer J.M., Kononoff P.J., Tedeschi L.O., Jenkins T.C., Karges K., Gibson M.L. J. Dairy Sci. 2010. V. 93. P. 2803-2815. doi 10.3168/jds.2009-2460.

9. Yildiz E., Todorov N. Bulgarian J. Agric. Sci. 2014. V. 20. P. 428-446. https://journal.agrojournal.org/ download.php?articleID=635.

10. Marghazani I.B., Jabbar M.A., Pasha T.N., Abdullah M. Italian Journal of Animal Science. 2012. V. 11. N 1. P. 58-62. doi 10.4081/ijas.2012.e11.

11. Jayanegaraa A., Dewib S.P., Ridlaa M. Media Peternakan. 2016. V. 39. N 3. P. 195-202. doi 10.5398/medpet.2016.39.3.195..

12. Adiwinarti R., Kustantinah K., Budisatria I.G.S., Rusman R., Indarto E. Asian J. Anim. Sci. 2016. V. 10. N 4. P. 262-267. doi 10.3923 / ajas.2016.262.267.

13. Goh C.H., Nicotra A.B., Mathesius U. Plant Cell Environ. 2016. V. 39. P. 883-896. doi 10.1111/pce.12672.

14. Laconi E.B., Jayanegara A. Asian Australas. J. Anim. Sci. 2015. V. 28. P. 343-350. doi 10.5713/ajas.13.0798.

15. Mahima, Kumar V., Tomar S.K., Roy D., Kumar M. Vet. World. 2015. V. 8. P. 551-555. doi 10.14202/vetworld.2015.551-555.

16. Adiwinarti R., Budisatria I.G.S., Kustantinah K., Rusman R., Indarto E. Vet. World. 2019. V. 12. P. 890-895. doi: 10.14202/vetworld.2019.890-895.

17. Csapo J., Albert Cs., Kiss D. Acta Univ. Sapientiae, Alimentaria. 2018. V. 11. P. 110-127. doi 10.2478/ausal-2018-0007.

18. Ayyat M.S., Al-Sagheer A., Noreldin A.E., Abdel-Hack M.E., Khafaga A.F., Abdel-Latif M.A., Swelum A.A., Arif M., Salem A.Z.M. Animal Biotechnology. 2019. P. 1-16. doi 10.1080/10495398.2019.1653314.

19. Kamalak, A., Canbolat, O., Gurbuz, Y., Ozay O. KSU J. Science and Engineering. 2005. V. 8. N 2. P. 84-88. https://www.researchgate.net/publication/266480414.

20. Грудина Н.В., Грудин Н.С., Быданова В.В. Доклады Российской академии сельскохозяйственных наук. 2015. №6. C. 47-49. https://elibrary.ru/download/ elibrary_24834079 32803170.pdf.

21. Peixoto E.L.T., Morenz M.J.F., Da Fonseca C.E.M., Dos Santos Moura E., De Lima K.R., Lopes F.C.F., Da Silva 
Cabral L. Semin. Agrar. 2015. V. 36. P. 3421-3430. doi 10.5433/1679-0359.2015v36n5p3421.

22. Foiklang S., Wanapa, M., Norrapoke T, Asian-Australas. J. Anim. Sci. 2016. V. 29. P. 1416-1423. doi 10.5713 / ajas.15.0689.

23. Tayengwa T., Mapiye C. Sustainability. 2018. V. 10. N 10. P. 3718. doi 10.3390/su10103718.

24. Zhao G., Diao H.-J., Zong W. Food Science and Technology International. 2013. V. 19. N 2. P. 153. doi $10.1177 / 1082013212442191$.

25. Алеева С.В., Лепилова О.В., Кокшаров С.А. Изв. вузов. Технология текстильной промышленности. 2017. №1. C. 319-324. https://ttp.ivgpu.com/wpcontent/uploads/2017/05/367_63.pdf.

26. Алеева С.В., Лепилова О.В., Курзанова П.Ю., Кокшаров С.A. Изв. вузов. Химия и химическая технология. 2018. Т. 61. №2. С. 80-85. doi 10.6060/ tcct.20186102.5512.

27. Алеева С.В., Лепилова О.В., Кокшаров С.А. Изв. вузов. Технология текстильной промышленности. 2018, №4. C. 89-95. https://ttp.ivgpu.com/wp-content/ uploads/2018/11/376_19.pdf.

28. Koksharov S.A., Aleeva S.V, Lepilova O.V. International Journal of Chemical Engineering. 2019, 4137593, p. 1-11. doi 10.1155/2019/4137593.

29. Патент RU №2666769. Опубл. 12.09.2018. БИ №26. https://yandex.ru/patents/doc/ RU2666769C1_20180912.

30. Dawod A., Ahmed H., Abou-Elkhair R., Elbaz H.T., Taha A.E., Swelum A.A., Alhidary I.A., Saadeldin I.M., Al-Ghadi M.Q., Ba-Awadh H.A., Hussein E.O.S, AlSagheer A.A. Animals. 2020. V. 10. N 3. P. 436. doi 10.3390/ani10030436.

31. Broderick G., Muck R.E. Journal of Dairy Science. 2009. V. 92. N 3. P. 1281-1303. doi 10.3168 / jds.20081303.

32. Rouches E., Herpoel-Gimbert I., Steyer J.P., Carrere H. Sustanable Energy Rev. 2016. V. 59. P. 179-198. doi 10.1016/j.rser.2015.12.317.

33. Bennett J.W., Klich M. Clinical microbiology reviews. 2003. V. 16. N 3. P. 497-516 doi 10.1128/ CMR.16.3.497-516.2003.

34. Ахмадышин Р.А., Канарский А.В., Канарская 3.А. Вестник Казанского технологического университета. 2007. №2. C. 88-103. https://elibrary.ru/download/ elibrary_9954946_17885110.pdf.

35. Gruber-Dorninger C., Novak B., Nagl V., Berthiller F. Journal of Agricultural and Food Chemistry. 2017.V. 65. N 33. P. 7052-7070. doi 10.1021/acs.jafc.6b03413.

36. Wielogórska E., MacDonald S., Elliot C.T. World Mycotoxin. 2016. V. 9. P. 419-433. doi 10.3920/ WMJ2015.1919.

37. Vila-Donat P., Marun S., Sanchis V., Ramos A.J. Food and chemical toxicology. 2018. V. 114. P. 246-259. doi 10.1016/j.fct.2018.02.044.

38. Freimund S., Sauter M., Rys P. Journal of Environmental Science and Health. 2003. V. 38. P. 243-255. doi 10.1081/PFC-120019892.

39. Yiannikouris A., Francoi J., Poughon L., Dussap C.G., Bertin G., Jeminet G., Jouany J.P. Journal of Agricul- tural and Food Chemistry. 2004. V. 52. P. 3666-3673. doi $10.1021 /$ jf035127x.

40. Nordi E.C.P., Costa R.L.D., David C.M.G., Parren G.A.E., Freitas A.C.B., Lameirinha L.P., Katiki L.M., Bueno M.S., Quirino C.R., Gama P.E., et al. Vet. Parasitol. 2014. V. 205. P. 532-539. doi 10.1016/j.vetpar.2014.09.015.

41. Максимально допустимые уровни (МДУ) микотоксинов в кормах для сельскохозяйственных животных. Утвержд. ГУВ Минсельхоза СССР N 434-7 от 01.02.89. http://docs.cntd.ru/document/1200117692.

42. Rodrigues I., Naehrer K. Toxins. 2012. V. 4. P. 663-675. doi 10.3390/toxins4090663.

43. Pinto V.E., Patriarca A. Methods Mol Biol. 2017. V. 1542. P. 13-32. doi 10.1007/978-1-4939-6707-0_2.

44. Kozak L., Szilagyi Z., Toth L., Pocsi I., Molnar I. Appl. Microbiol Biotechnol. 2019. V. 103. N 4. P. 1599-1616. Doi 10.1007 / s00253-018-09594-x

45. Manafi M., Narayanaswamy H.D., Pirany N. African Journal of Agricultural Research. 2009. V. 4. P. 141-143. doi 10.3390/toxins 10120510 .

46. Кудряшов А.Ю., Кокшаров С.А., Пашин Е.Л. Изв. вузов. Технология текстильной промышленности. 2009. № 5. C. 3-5. https://ttp.ivgpu.com/wp-content/ uploads/2015/11/320_1.pdf.

47. Кокшаров С.А., Алеева С.В., Скобелева О.А., Кудряшов А.Ю. Изв. вузов. Химия и химическая технология. 2011. Т. 54. №6. С. 93-96. https://elibrary.ru/ download/elibrary_16388550_77962472.pdf.

48. Алеева С.В., Кокшаров С.А. Рос. хим. ж. 2011. T. LV. №3. C. 46-58. https://elibrary.ru/download/ elibrary_17113163_45941445.pdf.

49. Koksharov S., Aleeva S., Lepilova O. Autex Res. J. 2015. V. 15. N 3. P. 215-225. doi 10.1515/aut-20150003

50. Алеева С.В., Чистякова Г.В., Лепилова О.В, Кокшаров С.А. Журнал физической химии. 2018. Т. 92. № 8. C. 1308-1315. doi 10.1134/S0036024418080022.

51. Koksharov S.A., Aleeva S.V., Lepilova O.V. Molecular Liquids. 2019. V. 283. P. 606-616. doi 10.1016/j.molliq.2019.03.109.

52. Лепилова О.В., Кокшаров С.А., Алеева С.В. Журнал прикладной химии. 2018. Т. 91. №1. С 68-73. doi 10.1134/S1070427218010147.

53. Koksharov S.A., Aleeva S.V, Lepilova O.V. Key Engineering Materials. 2019. V. 816. P. 333-338. doi 10.4028/www.scientific.net/KEM.816.333.

54. Кокшаров С.А., Алеева С.В. Биохимическая модификация полисахаридов в процессах текстильного производства // Научные основы химической технологии углеводов. Под ред. А.Г. Захарова. - М.: Изд. ЛКИ, 2008. С. 401-523. https://urss.ru/cgi-bin/db.pl?la ng $=$ Ru\&blang $=$ ru\&page $=$ Book\&id $=57048$.

55. Ivanchenko O., Aronova E., Balanov P., Smotraeva I. IOP Conf. Series: Earth and Environmental Science. 2019. V. 337. 012037. 5 p. doi 10.1088/17551315/337/1/012037.

56. Kochkina N.E., Skobeleva O.A., Khokhlova Yu.V. Particul Sci Technol. 2017. V. 35. N 3. P. 259-264. doi 10.1080/02726351.2016.1153546. 
57. Алеева С.В., Чистякова Г.В., Кокшаров С.А. Изв. вузов. Химия и химическая технология. 2009. T. 52. №10. C. 118-121. https://elibrary.ru/download/ elibrary_12969035_29916512.pdf.

58. Boyd G.E., Adamson A.W., Myers L.S. J. Am. Chem. Soc. 1947. V. 69. P. 2836-2848. http://dns2.asia.edu. tw/ ysho/YSHO-English/1000 WC/PDF/J Ame Che Soc69, 2836.pdf.

59. Weber Jr.W.J., Morris J.C. J. Sanit. Eng. Div. 1963. V. 89. P. 31-59. https://www.scirp.org/reference/ReferencesPapers.aspx?ReferenceID=1215797.

60. Маслова М.В., Иваненко В.И., Герасимова Л.Г. Журнал физической химии. 2019. Т. 93. № 7. С. 10021008. doi 10.1134/S0044453719060219.

61. Ho Yu.Sh., Ng J.C.Y., McKay G. Separation and purification methods. 2000. V. 2. N 29. P. 189-232. doi 10.1081/SPM-100100009.

62. Ho Yu.Sh. Scientometrics. 2004. V. 1. N. 59. P. 171177. doi 10.1023/B:SCIE.0000013305.99473.cf.

63. Douven S., Paez C.A., Gommes C.J. Journal of Colloid and Interface science. 2015. V. 448. P. 437-450. doi 10.1016/j.jcis. 2015.02.053.

64. Shepherd W. Materiae Vegetabiles. 1956. V. 2. P. 58-63. doi 10.1007/BF01889775.

65. Pretsch E., Buhlmann Ph., Badertscher M. Structure Determination of Organic Compounds. Tables of Spectral Data. Berlin: Springer-Verlag Berlin Heidelberg, 2009. P. 269-336. https://link.springer.com/book/10.10 07\%2F978-3-540-93810-1.

66. Khotimchenko M., Kovalev V., Khotimchenko Yu. J. Hazardous Mater. 2007. V. 149. P. 693-699. doi 10.1016/j. jhazmat.2007.04.030.

67. Кайшева Н.Ш., Кайшев А.Ш. Журнал физической химии. 2015. Т. 89. №7. С. 1122-1128. doi 10.7868/ S0044453715070146.

68. Yapo B.M. Koff K.L. Carbohydr Polym. 2013. V. 92. N 1. P. 1-10. doi: 10.1016/j.carbpol.2012.09.010.

69. Zhang B., Hu B., Nakauma M., Funami T., Nishinari K., Draget K.I., Phillips G.O., Fang Y. Food Res Int. 2019. V. 116. P. 232-240. doi: 10.1016 / j. foodres.2018.08.020.

70. Morris E.R., Powell D.A., Gidley M.J., Rees D.A. J. Mol. Biol. 1982. V. 155. N 4. P. 517-531. doi 10.1016/00222836(82)90484-3.

71. Padayachee A., Day L., Howell K., Gidley M.J. Critical Reviews in Food Science and Nutrition. 2017. V. 57. N 1. P. 59-81. doi 10.1080/10408398.2013.850652.

72. Assifaoui A., Lerbret A., Uyen H.T.D., Neiers F., Chambin O., Loupiac C., Cousinc F. Soft Matter. 2015. V. 11. N 3. P. 551-560. doi 10.1039/c4sm01839g.

73. Plazinski W. J. Comput. Chem. 2011. V. 32. N 14. P. 2988-2995. doi: 10.1002/jcc. 21880.

74. Gawkowska D., Cybulska J., Zdunek A. Polymers. 2018. V. 10. P. 762-787. doi 10.3390/polym10070762.

75. Микиина П.В., Петрова А.А., Файзуллин Д.А., Зуев Ю.Ф., Горшкова Т.А. Биохимия. 2015. Т. 80. № 7. C. 1088-1098. doi 10.1134/S000629791507010X.
76. Day A., Ruel K., Neutelings G., Cronier D., David H., Hawkins S., Chabbert B. Planta. 2005. V. 222. P. 234245. doi 10.1007/s00425-005-1537-1.

77. Huis R., Morreel K., Fliniaux O., Lucau-Danila A., Fénart S., Grec S., Neutelings G., Chabbert B., Mesnard F., Boerjan W., Hawkins S. Plant Physiol. 2012. V. 158. N 4. P. 1893-1915. doi: 10.1104 / PP. 111. 192328.

78. Khotimchenko M., Makarova K., Khozhaenko E., Kovalev V. Int. J. Biol. Macromol. 2017. V. 97. P. 526-535. doi 10.1016 / j. ijbiomac.2017.01.065.

79. Чистякова Г.В., Кокшаров С.А. Журнал общей химии. 2014. Т. 84. №4. С. 689-692. doi 10.1134/ S1070363214040276э.

80. Jakóbik-Kolon A., Mitko K., Bok-Badura J. Materials. 2017. V. 10. N 7. P. 844-855. 25767125. doi:10.3390/ ma10070844.

81. Boumediene M., Benaïssa H., George B., Molina St., Merlin A. J. Mater. Environ. Sci. 2018. V. 9. N 6. P. 1700-1711. doi 10.26872/jmes.2018.9.6.190.

82. Hurairah S.N., Lajis N.M., Halim A.A. Journal of Geoscience and Environment Protection. 2020. V. 8 N 2. P. 128-143. doi: 10.4236 / gep.2020.82009.

83. Kumar N.S., Asif M., Poulose A.M., Suguna M., AlHazza M.I. Processes. 2019. V. 7. N 10. P. 757. doi 10.3390/pr7100757.

84. Chatterjee A., Schiewer S. Chem. Eng. J. 2014. V. 224. P. 105-116. doi 10.1016/ j. cej.2013.12.017.

85. Korzh E.A., Smolin S.K., Klymenko N.A. Journal of Water Chemistry and Technology. 2016. V. 38. N 4. P. 187-193. doi 10.3103/S1063455X16040019.

86. Campos N.F., Barbosa C.MBM, RodriguezDiaz J.M., Duarte M.MMB. Adsorption Science and Technology. 2018. V. 36. N 1. P. 1-17. doi 10.1177/0263617418773844.

87. Ma Y., Zhang B., Ma H, Yu M., Li L., Li J. Sci. China Mater. 2016. V. 59. N 1. P. 38-50. doi 10.1007/s40843016-0117-y.

88. Сазонова В.Ф., Перлова О.В., Перлова Н.А., Поликарпов А.П. Коллоидный журнал. 2017. Т. 79. №2. C. 219-226. doi 10.7868/S0023291217020136.

89. Полянский Н.Г., Горбунов Г.В., Полянская Н.Л. Методы исследования ионитов. М.: Химия, 1976. 208 c. https:// www.studmed.ru/polyanskiy-ng-gorbunov-gv-polyanskaya-nl-metody-issledovaniya-ionitov_14a1476e3f4.html.

90. Varadwaj G.B.B., Parida K., Nyamori V.O. Inorg. Chem. Front. 2016. V. 3 P. 1100-1111. doi 10.1039/C6QI00179C.

91. Wang R.H., Zhu X., Qian W., Hong Z. Journal of Soils and Sediments. 2017. V. 17. N 10. P. 1-9. doi 10.1007 / s11368-017-1702-8.

92. Tuchowska M., Muir B., Kowalik M., Socha R.P., Bajda T. Materials. 2019. V. 12. 2253. doi 10.3390/ma12142253.

93. Конькова Т.В., Морозов А.Н., Канделаки Г.И., Алехина М.Б. Журнал физической химии. 2018. Т. 92. № 11. C. 1700-1704. doi 10.1134/S0044453718110171.

94. Zhu T.T., Zhou C.H., Kabwe F.B., Wu Q.Q. Applied Clay Science. 2019. V. 169. P. 48-66. doi 10.1016/ j. clay.2018.12.006. 